\title{
Molar Volume, lonic Radii in Stoichiometric and Nonstoichiometric Metal Oxides
}

\author{
Andrzej Stokłosa \\ Cracow University of Technology, \\ Faculty of Chemical Engineering and Technology, Cracow, \\ Poland
}

\section{Introduction}

Metal oxides are a group of compounds that are now intensively studied because of their wide use in modern ceramic materials, composites, nano-composites, etc., with new special properties. Many oxides are used as electronic materials for their electrical, magnetic and optical properties. The mechanisms of corrosion of metals and their alloys, as well as the mechanism of reduction in metallurgical processes depends on metal oxides formed in these processes. In contrast to the main group metal oxides, generally stoichiometric, the transition metal oxides feature bigger diversity in their properties. Their electrical properties vary from metallic to semiconductor. Many oxides show significant deviations from stoichiometry. The transition metals form numerous oxide phases with ions in different oxidation states, depending on the oxygen pressure. They are a group of compounds in which structure and properties depend strongly on the metal type because of a change in interactions of ionic-covalent character. An especially important issue becomes the relation between the structure and ionic radii sizes on the one hand and properties on the other. One of the important issues is a change in spheres occupied by ions (ionic radii) dependent on the interaction character, coordination number, oxidation degree (formal and real charge), metal type in the case of hetero-metallic oxides, dopants, etc. A particularly complex problem occurs in the case of oxides. In compact structures, in which close packing of anions is assumed, not all voids are occupied by cations. Besides, ionic defects occur in significant concentrations in many oxides. In these oxides, in spite of the conservation of the coordination number of cations, often having different oxidation states, distortions of coordination polyhedra occur which results in various bond lengths in the crystal. Next problem is the size of the sphere occupied by ions in polymorphic forms differing by lattice parameters and often having deformed structures. For the cases mentioned above, the problem of the ion radius has not been solved practically.

For many years attempts have been made to find relatively simple parameters which could allow to investigate the changes in the properties of crystalline compounds. One of first parameters was ionic radius. A method of its calculation was proposed as early as in 1926 by Goldschmidt (Goldschmidt, 1926) and many other methods were described later (Pauling, 1927; Zachariansen, 1931; Ahrens, 1952, 1953). To differentiate the ability of ions to interact, Cartledge (Cartledge, 1928, 1930) and Ahrens (Ahrens, 1952, 1953) introduced a parameter 
being the ratio of ion charge or its ionisation energy to ion radius. The above parameters have been used in mineralogy for geochemical characteristics of ions, their weathering resistance or to determine the sequence of crystallisation of different phases in an alloy. A widely used parameter differentiating the properties of atoms of the elements is the scale of electronegativity introduced by Pauling (Pauling, 1932, 1960). Also other experimental scales, developed later, are in common use (Mulliken, 1934, 1935; Sanderson, 1976; Allen, 1998; Allred \& Rochow, 1958; Görlich, 1989a). For the purpose of characterisation of compounds or ions Parr (Donnelly \& Parr, 1978; Parr et al., 1983) introduced absolute electronegativity. It is possible to calculate it theoretically, basing on the density functional theory (Hohenberg \& Kohn, 1964, Kohn, et al., 1996). The properties of ions or molecules can be described also by values derived from electronegativity, as acidity and basicity (Pearson, 1997; Komorowski, 1993) or effective nuclear charge of the ion (Görlich, 1989b, 1990; Stokłosa et al., 2004). For the purpose of classification of the bonds in solid state, Pauling (Pauling, 1929) introduced bond ionicity and bond strength parameters. The above concepts were developed in a bond-valence model proposed by Browns (Brown, 1992, 2002), relating bond energy to its length. Most of the above parameters are evaluated basing on the quantities determined for isolated ions and they can be used in the analysis of ionic compounds. However, they are less useful in the analysis of the properties of oxides. This is due to the existence of ionic-covalent bond in oxides. Its character varies significantly with the position in the table of elements.

The development of the solid state theory has created strong theoretical basis for the description of interactions between atoms in a crystal. The electronic structure model, resulting from these interactions, allows identifying electrical, magnetic and optical properties of a compound. Today, the development of computational methods and the numerical capabilities of big computers allow calculating the interactions in quite big crystalline clusters, and thus to determine their properties. Nevertheless there is no data allowing detailed analysis of the properties of the oxides to be performed.

Hence, in spite of the development of chemistry and physics of solids, there are still open problems: Why some transition metal oxides show significant deviations from stoichiometric compositions (e.g. oxides of $\mathrm{Ti}, \mathrm{V}, \mathrm{Nb}, \mathrm{Fe}$ )? Why many metals form few or a dozen of oxide phases? What is the reason for high melting temperatures of some phases, while others have low melting temperatures, so in what way the bond energy varies and why, etc.

The present work proposes to introduce an effective (mean) ionic radius (ionic sphere) based on molar volume obtained from X-ray studies for comparison of the properties of metal oxides depending on the ion type and size. It would allow distinguishing groups of oxides, not merely simple oxides but also complex ones, containing various cations (dopes) and following or predicting their properties, which was practically impossible when based on tabulated values of ionic radii. The analysis of the relationship between molar volume of metal oxides and their ion radii was discussed. A linear dependence was found for ionic radii versus the cube root of molecular volume standardised per oxygen atom $\left(\mathrm{M}_{\mathrm{a} / \mathrm{b}} \mathrm{O}\right)$ of $\mathrm{MO}$ oxides of alkali earth metals, $\mathrm{M}_{2} \mathrm{O}$ oxides of alkali metals and $\mathrm{MO}_{2}$ oxides of f-electron metals, and parameters of the linear equation were calculated. This equation makes it possible to predict mean ionic radii of metals in compact structures of polymorphic forms of oxides, mixed-valence oxides and oxides showing deviation from stoichiometry, otherwise not accessible. 
Presented also is the problem of changes in distances between oxygen atoms (ions), depending on the metal type, metal charge, polarization capabilities, composition and crystallographic structure of metal oxides. Changes in ion packing density in oxides have also been presented. It has been shown that these changes depend not only on ionic radii, but also on the interaction character (interatomic bonds).

\section{Molar volume and composition of metal oxide}

One of parameters characterizing ions/atoms in a crystal, and therefore characterizing the properties of the compound is molar volume being a result of ion radii sizes and their interactions. It can be easily calculated using lattice parameters. However, there are difficulties in its use because individual types of oxides have different compositions. It is therefore possible to compare molar volumes of oxides of different metals, but of the same type (e.g. $\mathrm{MO}, \mathrm{M}_{2} \mathrm{O}_{3}$ ) and preferably having the same structure. It is nevertheless difficult to draw conclusions from changes of molar volumes of the oxides of the same metal differing by composition and structure type. That is why analyses of structures and properties of various oxides, which can be found in monographs on crystal chemistry and solid state chemistry (Adams, 1974; O’Keeffe \& Navrotsky, 1981; Wells, 1990; Rao \& Raveau, 1995) are performed usually for a given type of oxides.

There are few oxides that - considering a given type - have ideal geometric structure. Besides, many oxide phases show deviation from the stoichiometry, or metal ions are in different oxidation states, e.g. in ordered phases (Magnéli phases). A distortion of coordination polyhedra occurs in these oxides and as a result $\mathrm{M}-\mathrm{O}$ bond lengths are differentiated. Hence, the volume of an unit cell is well defined, however, it is much more difficult to determine "real" ion positions and distances between them. Besides, unit cells of oxides differing by structure and composition contain different numbers of molecules, making the comparison of their volumes impossible.

\subsection{Effective molar volumes of oxides}

A parameter which could be used to compare molar volumes of different oxides is the volume of the oxide of composition $\mathrm{M}_{\mathrm{a} / \mathrm{b}} \mathrm{O}$ (containing one mole of oxygen atoms). Therefore, using the structural data: structure type, lattice parameters or X-ray density, and number of molecules in an unit cell it is possible to calculate its volume. Dividing the volume of an unit cell $\left(V_{\mathrm{M}_{\mathrm{a}} \mathrm{O}_{\mathrm{b}}}\right)$ by the number of molecules $(\mathrm{Z})$ in an unit cell and by the number of oxygen atoms in the $\mathrm{M}_{\mathrm{a}} \mathrm{O}_{\mathrm{b}}$ molecule and multiplying it by the Avogadro number $\left(N_{\mathrm{A}}\right)$ one can obtain a volume further called effective molar volume of an oxide, containing one mole of oxygen atoms ( $\left.V_{\text {eff }}\right)$ (Stokłosa \& Laskowska, 2008a):

$$
\left(\left(\mathrm{V}_{\mathrm{M}_{\mathrm{a}} \mathrm{O}_{\mathrm{b}}} / \mathrm{Z}\right) / \mathrm{b}\right) \mathrm{N}_{\mathrm{A}}=\mathrm{V}_{\text {eff }}
$$

The dependence of the effective molar volume $\left(V_{\text {eff }}\right)$ of transition metal oxides on their composition (on the $\mathrm{a} / \mathrm{b}$ ratio ) is presented in Fig. 1. In the case of non-stoichiometric compounds of $\mathrm{M}_{1-\mathrm{y}} \mathrm{O}_{1-\mathrm{x}}$ type (oxides of $\mathrm{V}, \mathrm{Ti}, \mathrm{Nb}$ etc.) the real contents of metal and oxygen in an unit cell of these oxides were taken into account and then recalculated to the volume containing one mole of oxygen atoms. The above relations have been obtained for oxides undergoing mutual transformations. 


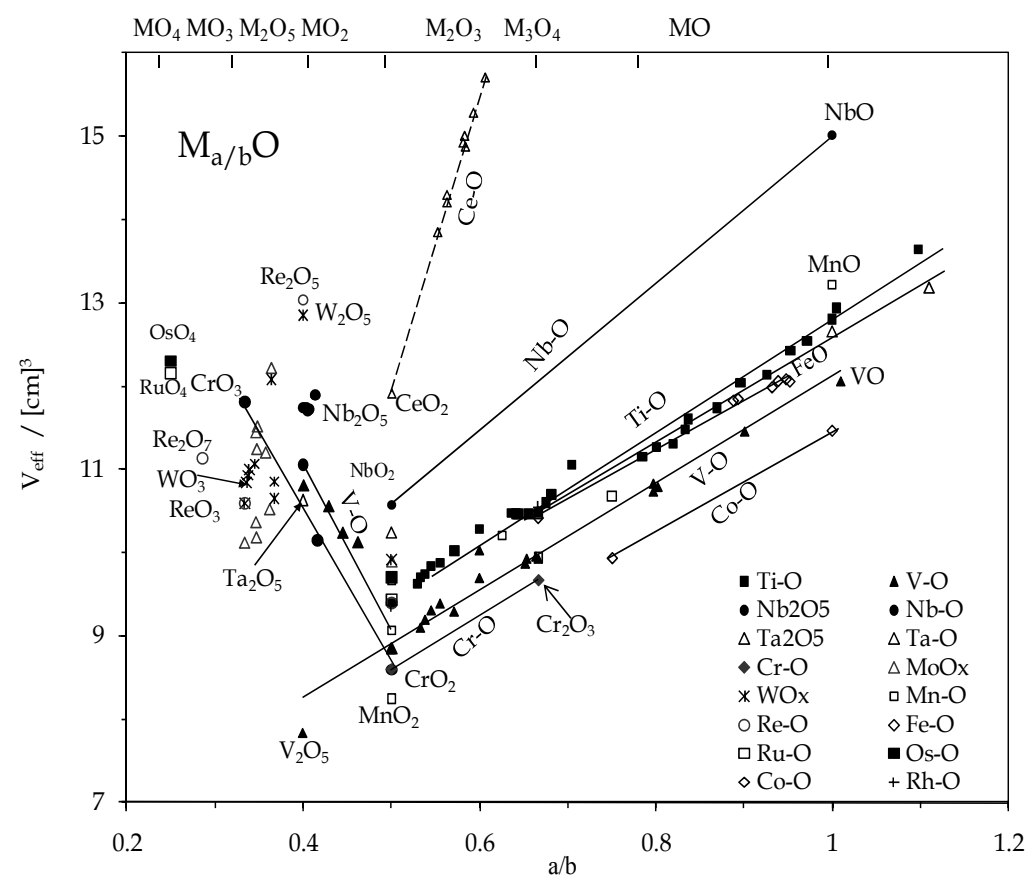

Fig. 1. The dependence of the effective molar volume ( $\left.V_{\text {eff }}\right)$ of the oxides $\mathrm{M}_{a / b} \mathrm{O}$ on the composition $(a / b)$ for the transition metal oxides and Ce oxides.

As it can be seen in Fig.1, the dependence of the effective molar volume of oxides on the $a / b$ ratio shows linear character in the composition range $0.5<a / b<1$. This character is conserved not only for the oxides having ions with the same charge $(2+, 3+)$ but also in the case of oxides showing deviation from the stoichiometry, for many oxide phases (Magnéli phases) with ions in different oxidation states and, as in the case of $\mathrm{Fe}_{1-\mathrm{y}} \mathrm{O}$ or $\mathrm{M}_{3} \mathrm{O}_{4}$ oxides with spinel structure, when metal ions have different coordination number, 4 or 6 (tetrahedral or octahedral).

As it can be seen in Fig. 1, in the case of the oxides with cations in higher oxidation state $\mathrm{M}^{\mathrm{z}^{+}>\mathrm{M}^{4+}(a / b<0.5)}$ the effective molar volume $\left(V_{\text {eff }}\right)$ increases. In the case of oxides of $\mathrm{Cr}, \mathrm{V}$ and Re the lines obtained have negative slope, while linear correlations are also rather good. The increase of molar volumes but lack of correlations occur in the case of many Magnéli phases or other ordered oxides of $\mathrm{W}, \mathrm{Mo}, \mathrm{Nb}$ with compositions in the range of $0.25<a / b<0.5$. In the case of $\mathrm{V}_{2} \mathrm{O}_{5}$ two significantly different volumes were determined. The $\mathrm{V}_{2} \mathrm{O}_{5}$ oxide with monoclinic structure has small volume, correlating with volumes of the oxides $\mathrm{VO} \rightarrow$ $\mathrm{VO}_{2}$, while $\mathrm{V}_{2} \mathrm{O}_{5}$ with rhombohedral structure, having bigger volume, correlates with the oxides having composition $a / b<0.5$.

On the other hand, the dependence of the molar volume $\left(V_{\text {eff }}\right)$ on the composition for $f$ electron metal oxides is presented in Fig. 2. 


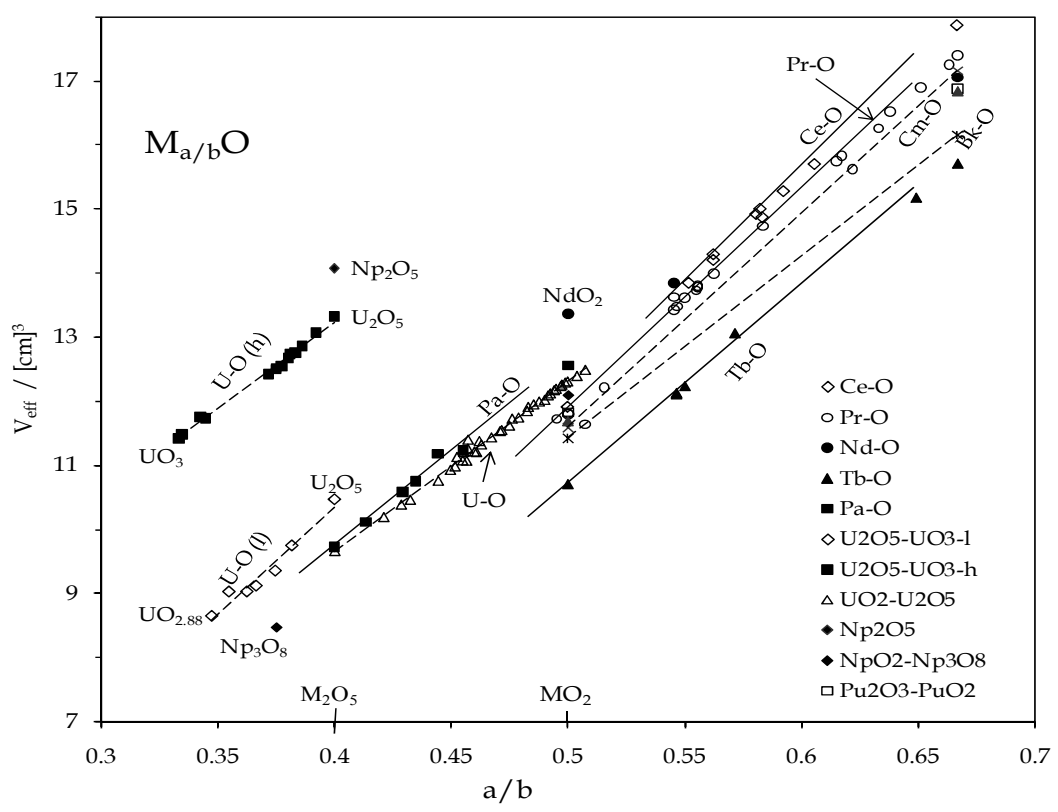

Fig. 2. The dependence of the effective molar volume $\left(V_{\text {eff }}\right)$ of the oxides $\mathrm{M}_{a / b} \mathrm{O}$ on the composition $(a / b)$ for $f$-electron metal oxides, $(-)$ - lanthanides, (- -) - actinides.

As it can be seen in Fig. 2, for the oxides with compositions in the range of $0.666>a / b>0.4$, for systems containing many phases (oxides of $\mathrm{Ce}, \mathrm{Pr}, \mathrm{Tb}, \mathrm{Pa}, \mathrm{U}$ ) as well as for systems containing only oxides $\mathrm{M}_{2} \mathrm{O}_{3}$ and $\mathrm{MO}_{2}$ (with exception of the $\mathrm{Nd}-\mathrm{O}$ system), the slopes of the obtained lines are similar. In the case of uranium oxide phases three groups of crystallographic data were found. Apart from oxide phases with compositions varying in the range of $0.4<a / b<0.5$, phases of the same or close composition significantly differing by volume were found in the composition range of $0.33<a / b<0.4$. The obtained dependencies have practically the same slopes.

Furthermore, the dependence of the molar volume on the composition for oxides of alkali metals and other metals forming $\mathrm{M}_{2} \mathrm{O}$ oxides and also for alkaline earth metal oxides. is presented in Fig. 3 and for group 11-15 oxides is depicted in Fig. 4.

A bigger number of phases in this group of oxides is observed only in the case of row 6 metal oxides ( $\mathrm{Tl}, \mathrm{Pb}$ and $\mathrm{Bi}$ ), and the obtained correlations are worse in comparison to other oxides. The slope for the oxides of $\mathrm{Pb}, \mathrm{Bi}$ is three times bigger than that for the transition metal oxides. For comparison, the dependence of $V_{\text {eff }}$ on the composition for the Ce-O system oxides was marked in Fig. 1 and 4 . As it can be seen, either values and slopes for the above lines for oxide phases of $f$-electron metals significantly deviate from the relationship obtained for the oxides of $d$-electron metals. On the other hand, the obtained linear function parameters are close to the parameters for the main group metal oxides $(\mathrm{Bi}, \mathrm{Pb})$. 


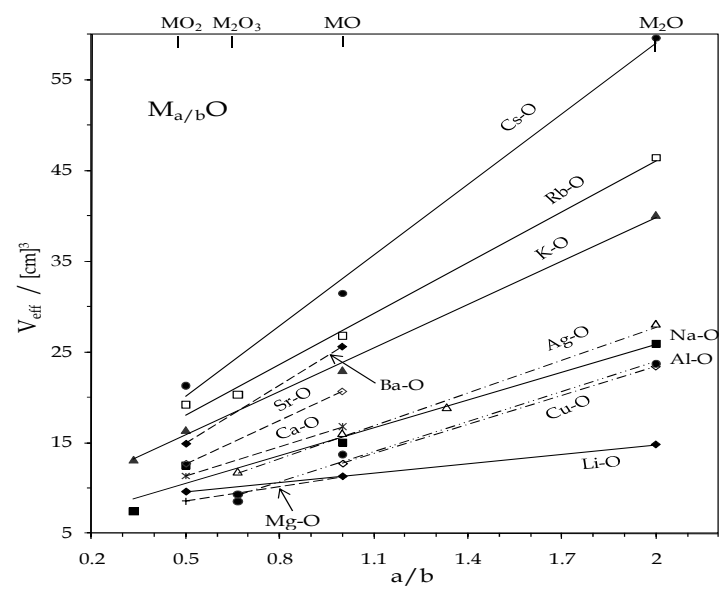

Fig. 3. The dependence of the effective molar volume ( $\left.V_{\text {eff }}\right)$ of the oxides $\mathrm{M}_{a / b} \mathrm{O}$ on the composition $(a / b)$ for the alkali metal oxides, the oxides of $\mathrm{Al}, \mathrm{Ag}, \mathrm{Cu}$ and the alkaline earth metal oxides.

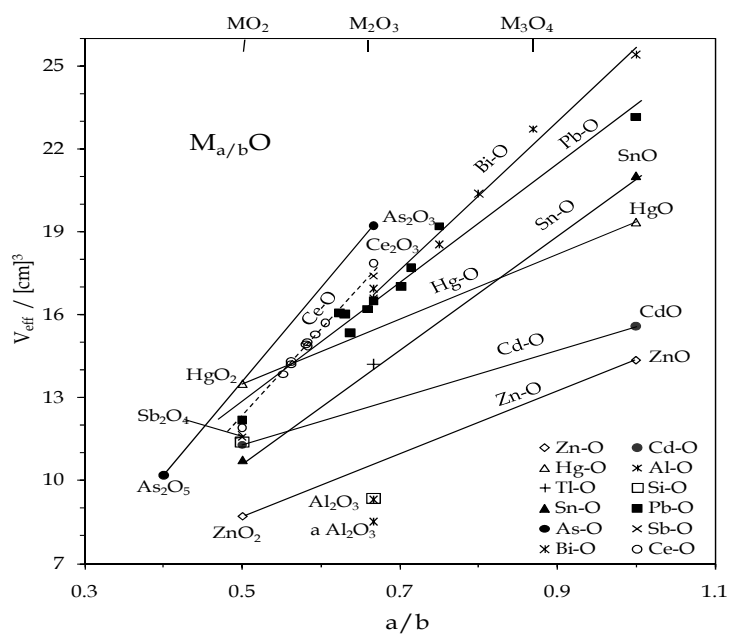

Fig. 4. The dependence of the effective molar volume ( $\left.V_{\text {eff }}\right)$ of the oxides $\mathrm{M}_{a / b} \mathrm{O}$ on the composition $(a / b)$ for the group 11-15 metal oxides and Ce oxides.

\subsection{Compact structures}

The obtained linear character of the dependence of the effective molar volume $\left(V_{\text {eff }}\right)$ on the composition $(a / b)$ in the range of composition changes of $2>a / b>0.5$ (in the case of transition metal oxides $1>a / b>0.5$, and $0.666>a / b>0.35$ in the case of $f$-electron metal oxides), should be considered as a general relationship for the phases undergoing mutual transformations. The observed decrease of the molar volume of the oxides ( $\left.V_{\text {eff }}\right)$ is a result of smaller quantity of 
metal ions per one mole of oxygen, and of smaller radii of ions in higher oxidation states $(3+$, $4+)$. The character of the change of molar volume results from the tendency of the individual oxides to form compact structures, typical for compounds with non-oriented ionic bond or ionic-covalent one. The compact structures are structures where anions form the closepackaging lattice and cations are located in its voids. The term close-packed structures is explicitly defined, in the case of metals it equals the closest possible packaging of spheres. However, there is no precise definition of compact structure for ionic compounds (Von Meerssche \& Dupont, 1976; Wells, 1990; West, 1996)). Doubts emerge especially if the systems have low symmetry, when significant number of voids in anion sublattice is not occupied by cations or/and the anionic sites are not occupied (there are anion vacancies). Besides, the distances between oxygen ions are much bigger than their radii.

Considering the results obtained one can state that compact structures are adopted by:

- $\quad \mathrm{M}_{\mathrm{a} / \mathrm{b}} \mathrm{O}$ oxides with composition in the range of $2>a / b>0.5$ (in the case of actinide oxides up to 0.33) having effective molar volumes of oxides $\left(\mathrm{M}_{a / b} \mathrm{O}\right)$ of the same metal decreasing linearly when the metal content decreases.

- Polymorphic forms of these oxides will also have compact structures, because slight changes of their molar volumes result from the change of interactions between ions/atoms caused by the change of temperature or pressure.

- Compact structures will be adopted also by the oxides of other metals, having the same compositions and structures as the oxides classified as compact structures.

Typical compact structures adopted by the individual oxides and oxide phases are NaCl-type structures (MO oxides), $\mathrm{Al}_{2} \mathrm{O}_{3}$-type hexagonal structures and rutile-type $\left(\mathrm{TiO}_{2}\right)$ structures with which most $\mathrm{MO}_{2}$ oxides crystallize. In the case of $f$-electron metal oxides these structures are: cubic $\mathrm{Mn}_{2} \mathrm{O}_{3}$-type structures, and $\mathrm{CaF}_{2}$-type structures in $\mathrm{MO}_{2}$ oxides. With the decrease of the metal content relative to oxygen in an oxide, the number of voids in the anionic sublattice not occupied by cations increases. As a result one can observe the transition from the close-packed structures of anions to a structure formed by coordination polyhedra connected by edges and/or corners despite the fact that the anionic sublattice practically does not change (the structures still have the character of compact structures). In many cases also other types of structures may appear, with lower symmetry but with similar volume, e.g. as in the case of homologue series $\mathrm{V}_{\mathrm{n}} \mathrm{O}_{2 \mathrm{n}-1}$. The decrease of system symmetry occurs as a result of distortion of the coordination polyhedra or as a result of ordering of point defects. The above perturbations cause the deviations from the ideal geometric structure.

Starting from the $\mathrm{M}_{2} \mathrm{O}$ or $\mathrm{MO}$ oxides, having biggest chemical potential of metal, as a result of the increase of oxygen potential in gas atmosphere, the transformation into an oxide with lower metal content is forced (the $\mathrm{M} / \mathrm{O}$ ratio decreases), where ions must be in higher oxidation states (to compensate the oxygen charge) and atoms tend to the closest possible packing. The effective molar volumes of the individual oxides are successively smaller and this change is continuous in the case of formation of point defects, or stepwise when the ordered structures are formed but the same linear character of the dependence of $V_{\text {eff }}$ on the $a / b$ ratio is practically conserved.

The formation of compact structures is fully consistent with the fact that the arrangement of atoms in the space result from their sizes and the optimal interactions between atoms/ions, being superior relative to the ideal structure with highest possible symmetry. 


\subsection{Framework structures}

The increase of the effective molar volume with the decrease of the metal content, observed for most oxides, in the range of $0.25<a / b<0.5$, is also justified. The increase of the amount of oxygen atoms relatively to metal together with the presence of ions with high charges $\left(\mathrm{M}^{5+}\right.$ and/or $\mathrm{M}^{6+}$ ) cause the increase of the repulsive forces that lead to the increase of the effective molar volume of an oxide comparing to that of $\mathrm{MO}_{2}$ type oxide. The presence of ions in high oxidation states, as well as a significant contribution of the covalent bond (spd hybrid orbital's) causes that these oxides have significant bond energies, high enough to maintain the stability of the crystal. The observed linear increase of the volume $V_{\text {eff }}$ with the decrease of the $a / b$ ratio for the oxides of $\mathrm{Cr}, \mathrm{Re}, \mathrm{V}$ metals, and possibly also for other systems, comparing to the $\mathrm{MO}_{2}$ oxide, will be probably present in the case of the reversible transformation of these oxides (thermodynamically stable forms). The lack of correlation of the molar volume and the composition observed for many oxides of $\mathrm{W}, \mathrm{Mo}, \mathrm{Nb}$ etc. can indicate that these phases could be thermodynamically unstable. Most of these phases form homologues of type $\mathrm{M}_{n} \mathrm{O}_{2 n-m}$, which usually are created in the reduction process, when the oxygen is removed from the lattice sites (the mosaic structures or shear structures are created) (Rao \& Raveau, 1995). The phases formed in this way can accept the oxygen, but they are not created by the oxidation of $\mathrm{MO}_{2}$ oxide or metal. The formation of phases of this type does not result in the significant changes in the structure, despite the changes of system (crystal symmetry). There occurs ordering or agglomeration of point defects, the shear structures are formed, etc. The change of the volume of an unit cell may be small (or its volume can be a multiple of the unit cell), but the volume of the oxide containing one mole of oxygen atoms will significantly increase.

All these oxide phases can be included in the oxides with framework structure. These are oxides $\left(\mathrm{M}_{\mathrm{a} / \mathrm{b}} \mathrm{O}\right)$ with composition $\mathrm{a} / b<0.5$ and effective molar volumes bigger than those for the oxides of compact structures $\left(\mathrm{MO}_{2}\right)$ and the smallest metal content. In these oxides the coordination polyhedra can be identified, connected by corners, edges, etc. Most of these structures can be derived from the structure of the oxide $\mathrm{ReO}_{3}$ where the $\mathrm{MO}_{6}$ octahedrons form a regular lattice. Other cations can easily be included in the structure of this type of oxides. This leads to the stabilization of the structure, and as a result, one can obtain the perovskite-type structures or their variations.

\section{Molar volume of oxides and their ionic radii}

A parameter characterizing ions in a crystal, beside the ion formal charge, is the ion radius. Even if, according to quantum mechanics, ion radius has no theoretical meaning, it has become a useful parameter, defining space (a sphere) occupied by an ion in a crystal. Goldschmidt (Goldschmidt, 1926, 1931) assuming the additivity of interionic distance variations in compounds with a common ion and using the radii of $\mathrm{F}^{-}$and $\mathrm{O}^{2-}$ calculated by Wasastjerna (Wasastjerna, 1923) gave the first scale of ionic radii. Other methods of ionic radii calculation were proposed by Pauling (Pauling, 1927), Zachariansen (Zachariansen, 1931), Ahrens (Ahrens, 1952, 1953). The scale of effective ionic radii presently used was designed and verified by Shannon and Prewitt (Shannon \& Prewitt, 1969, 1970, 1976) and Jia (Jia, 1991). It is based on the radii of $\mathrm{F}^{-}=0.068 \mathrm{~nm}$ or $\mathrm{O}^{2-}=0.140 \mathrm{~nm}$. As it is known, the ion radius is dependent on the coordination number and on the ionic-covalent character of interionic interactions. The values of ionic radii calculated by various methods generally 
differ, due to the assumptions made and depending on the group of compounds used for the scale construction. A particularly complex problem occurs in the case of oxides. In compact structures, in which close packing of anions is assumed, not all voids are occupied by cations. Besides, ionic defects occur in significant concentrations in many oxides. In these oxides, in spite of the conservation of the coordination number of cations, often having different oxidation states, distortions of coordination polyhedra occur and, as a result, there are various bond lengths in the crystal (Wells, 1990; West, 1996; Brown, 1992 2002; Luehen et al., 1987; Kunz \& Brown, 1995; Nespolo et al., 2001; Lalik, 2005). Next problem is the size of the sphere occupied by ions in polymorphic forms differing by lattice parameters and often having deformed structures. For the cases mentioned above, the problem of ion radius has not been solved practically, it was, however, discussed in many works (Paulin, 1929; Fumi \& Tosi, 1964; Phillips \& Williams, 1965; Shannon \& Prewitt, 1969, 1970, 1976; Brown, 2002).

\subsection{Ionic radii and molecular volume of oxides}

Shannon and Prewitt (Shannon \& Prewitt, 1969, 1970, 1976) performed a verification of ionic radii in isotypic compounds, basing on the linear relation between the unit cell volume and the ionic radius $\left(\mathrm{r}^{3}\right)$. Next, Brisse and Knop (Brisse \& Knop, 1968) have demonstrated a linear relation between the radius and the cube root of the unit cell volume $\left(V_{\mathrm{M}_{2} \mathrm{O}_{3}}\right)^{1 / 3}$ for the $\mathrm{M}_{2} \mathrm{O}_{3}$ lanthanide oxides. A close relation between the radius and the cube root of the unit cell volume $\left(V_{\mathrm{MO}}\right)$ exists in the case of oxides with cubic $\mathrm{NaCl}$-type structure, because for the MO oxides $\sqrt[3]{V_{\mathrm{MO}}}$ is a sum of the diameters of metal ion $\left(2 r_{\mathrm{M}}^{\mathrm{c}}\right)$ and oxygen ion $\left(2 r_{\mathrm{O}}^{\mathrm{c}}\right)$ :

$$
\sqrt[3]{V_{\mathrm{MO}}}=2\left(\mathrm{r}_{\mathrm{M}}^{\mathrm{c}}+\mathrm{r}_{\mathrm{O}}^{\mathrm{c}}\right)=\sqrt[3]{4 \mathrm{~V}_{\mathrm{eff}}^{\mathrm{m}}} \equiv \sqrt[3]{\mathrm{V}_{\mathrm{eff}}^{\mathrm{m}}}=\sqrt[3]{2}\left(\mathrm{r}_{\mathrm{M}}^{\mathrm{c}}+\mathrm{r}_{\mathrm{O}}^{\mathrm{c}}\right)
$$

Similarly, the cube root of the volume occupied by the MO molecule $\left(V_{\text {eff }}^{\mathrm{m}}\right)^{1 / 3}$ is a linear function of the bond length. A question emerges - whether the cube root of the volume containing one molecule $\left(V_{\text {eff }}^{\mathrm{m}}\right)^{1 / 3}$ of any oxide $\left(\mathrm{M}_{a / b} \mathrm{O}\right)$ is a simple function of ionic radii, analogously as in the case of oxides with $\mathrm{NaCl}$-type structure (Eq.2).

The relation between the cube root of the effective molecular volume of oxides $\left(V_{\text {eff }}^{\mathrm{m}}\right)^{1 / 3}$ and the radius of respective cations $\left(r_{\mathrm{M}}\right)$ is plotted in Fig. 5 for a series of oxides. The volume of the molecule of $\mathrm{M}_{a / b} \mathrm{O}$ oxide was calculated dividing the unit cell volume by the number of molecules $(\mathrm{Z})$ and by the number of oxygen atoms $(\mathrm{b})$ in the $\mathrm{M}_{\mathrm{a}} \mathrm{O}_{\mathrm{b}}$ oxide. It will be further called the effective molecular volume $\left(\left(\mathrm{V}_{\mathrm{M}_{\mathrm{a}} \mathrm{O}_{\mathrm{b}}} / \mathrm{Z}\right) / \mathrm{b}=\mathrm{V}_{\text {eff }}^{\mathrm{m}}\right)$ (Stokłosa \& Laskowska, 2008b). As it can be seen in Fig.5, points from quite a big group of oxides are located on three approximately parallel lines. The highest line is formed by the alkali metal oxides with anti$\mathrm{CaF}_{2}$ structure and with metal ion coordination number $4(\mathrm{CN}=4)$. The points for the $\mathrm{ZnO}$, $\mathrm{BeO}, \mathrm{SiO}_{2}$ and $\mathrm{GeO}_{2}$ oxides with hexagonal structure $(\mathrm{CN}=4)$ lie close to this line. The points for $\mathrm{PtO}$ and $\mathrm{PdO}$ oxides, with tetragonal structure, in which metal ions have square planar coordination lie further away. Relatively close are located points for the $\mathrm{PbO}$ oxide with orthorhombic structure and $\mathrm{HgO}$ with tetragonal structure. The $\mathrm{CuO}$ and $\mathrm{AgO}$ oxides with monoclinic structure $(\mathrm{CN}=4)$ show bigger deviation. Significant molar volumes are found 
for the $\mathrm{Ag}_{2} \mathrm{O}$ and $\mathrm{Cu}_{2} \mathrm{O}$ oxides with rather untypical structure, where metal ions have coordination number of 2 . On the other hand, very good correlation is found for a series of oxides having coordination number 6 . These are $\mathrm{MO}$ alkaline earth metal oxides and $d-, f$ electron metal oxides, with $\mathrm{NaCl}$-type cubic structure, $\mathrm{M}_{2} \mathrm{O}_{3}$ with $a-\mathrm{Al}_{2} \mathrm{O}_{3}$-type hexagonal structure, $\mathrm{MO}_{2}$ oxides with rutile-type tetragonal structure and few main group metal oxides: $\mathrm{Al}_{2} \mathrm{O}_{3}, \mathrm{In}_{2} \mathrm{O}_{3}, \mathrm{Tl}_{2} \mathrm{O}_{3}$, with $\mathrm{a}-\mathrm{Al}_{2} \mathrm{O}_{3}$-type structure.

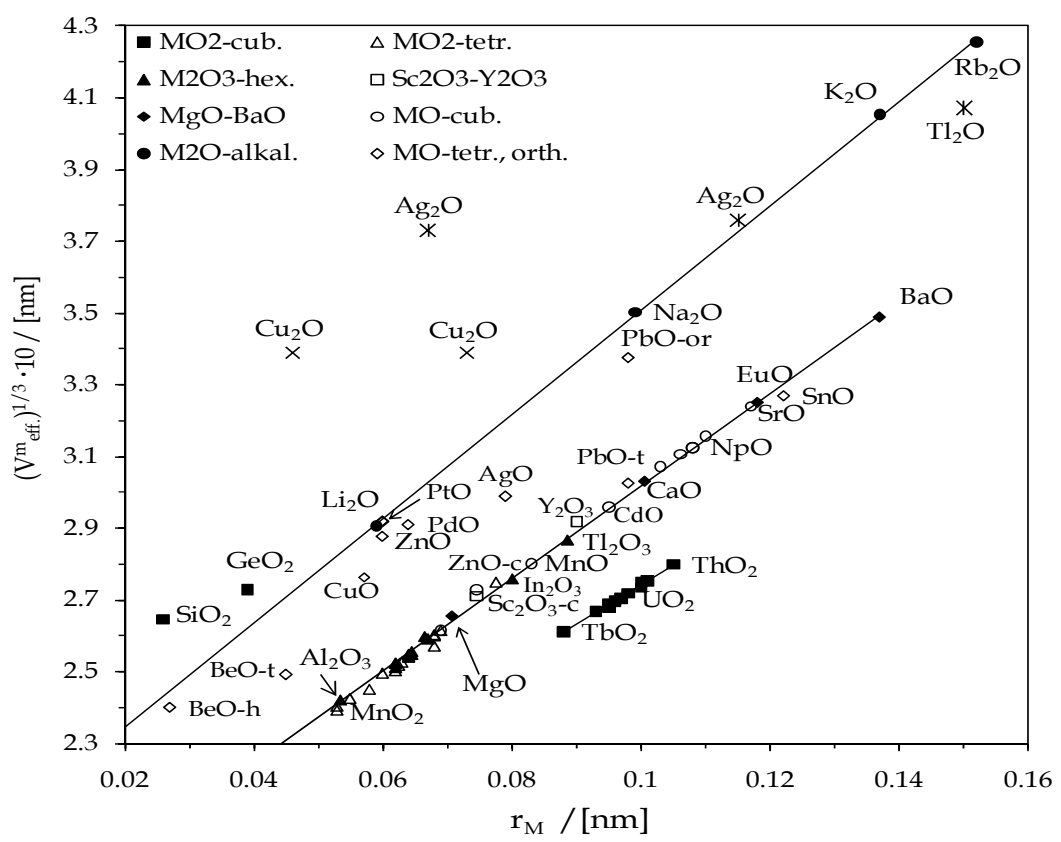

Fig. 5. The relation between the cube root of the molecular volume of oxides $\left(\sqrt[3]{V_{\mathrm{eff}}^{\mathrm{m}}}\right)$ and the radius of the respective metal ions.

The lowest line is formed by the $\mathrm{MO}_{2}$ oxides of $f$-electron metals with $\mathrm{CaF}_{2}$-type cubic structure with metal ion coordination number 8 . The parameters $\alpha$ and $\beta$ of the linear functions:

$$
\sqrt[3]{V_{\mathrm{eff}}^{\mathrm{m}}}=\alpha r_{\mathrm{M}}+\beta
$$

formed by individual groups of oxides are collected in Table 1 of the work (Stokłosa \& Laskowska, 2008b). The lines were obtained for the oxides of the same type, of the same metal and for the oxides of metals from the same group of the periodic table. In the case of $d$-electron oxides from the same group all the oxides with various oxidation states were considered. The correlation coefficients for most lines are high, $\mathrm{R}^{2}>0.98$, and the $\alpha$ parameter (slope) for individual groups of oxides varies only slightly. 


\subsection{Relative radii of metal ions}

The obtained correlations between $\left(V_{\text {eff }}^{\mathrm{m}}\right)^{1 / 3}$ and radii of metal ions with a given coordination number indicate that they are characteristic of compact structures (see Chapter 2). Assuming therefore, as previously (Shannon \& Prewitt, 1969, 1970), constant oxygen ion radius and the hypothesis of compact packing of anions in the oxide and using experimental relations between $\left(V_{\text {eff }}^{\mathrm{m}}\right)^{1 / 3}$ and the radii of metal ions with a given coordination number, for the oxides with "ideal" geometric structure a method of calculation of the relative radius of the sphere occupied by metal ion in a given oxide can be proposed. According to the obtained results, parameters of such equations can be evaluated basing on $\mathrm{M}_{2} \mathrm{O}$ alkali metal oxides for ions with coordination number $4, \mathrm{MO}$ alkaline earth metal oxides for ions with coordination number 6 and $\mathrm{MO}_{2}$ f-electron metal oxides for metal ions with coordination number 8 and. These oxides do not show deviation from stoichiometry (all sites in the structure are occupied) and considering the character of interionic interactions it can be assumed that the oxygen ion radius is constant. Thus, these equations are:

for oxides with coordination number 4 :

$$
\mathrm{r}_{\mathrm{M}}=0.6868 \sqrt[3]{\mathrm{V}_{\mathrm{eff}}^{\mathrm{m}}}-0.1731[\mathrm{~nm}]
$$

for oxides with coordination number 6:

$$
\mathrm{r}_{\mathrm{M}}=0.7622 \sqrt[3]{\mathrm{V}_{\mathrm{eff}}^{\mathrm{m}}}-0.1304[\mathrm{~nm}]
$$

for oxides with coordination number 8 :

$$
\mathrm{r}_{\mathrm{M}}=0.91 \sqrt[3]{\mathrm{V}_{\mathrm{eff}}^{\mathrm{m}}}-0.1494[\mathrm{~nm}]
$$

The parameters of these equations have been evaluated using molecular volumes of oxides calculated basing on lattice parameters and the table values of ionic radii by Shannon and Prewitt (Shannon \& Prewitt, 1969, 1970, 1976) (see Table 1, Stokłosa \& Laskowska, 2008b). The values of calculated relative radii of metal ions (relative to oxygen ion, $r_{O}=0.140 \mathrm{~nm}$ ) in oxides forming compact structures, using parameters of Eq.(4)-(6) and experimental values of molecular volumes in a series of selected oxides are listed in Table 2 of the work (Stokłosa \& Laskowska, 2008b). The trend lines marked in Fig. 5 and 6 and 7 have been evaluated for oxides used in the evaluation of the parameters of Eq.(4)-(6).

In Fig. 6 the points corresponding to table radii of $\mathrm{M}^{4+}$ ions (points $\bullet$ ) and the calculated values (points $\Delta$ ) for $\mathrm{r}_{\mathrm{O}}=0.14 \mathrm{~nm}$ were marked for the $\mathrm{MO}_{2}$ oxides of $f$-electron metals.

As it can be seen, the difference between these radii is about $0.002 \mathrm{~nm}$, which indicates that the interionic interactions lead to a shortening of bond lengths and if the oxygen ion radius is assumed to be $0.14 \mathrm{~nm}$, the metal ion radii should be smaller by about $0.002 \mathrm{~nm}$. On the other hand, if we assume oxygen ion radius for coordination number 4 as $0.138 \mathrm{~nm}$, i.e., the value proposed by Shannon and Prewitt (Shannon \& Prewitt, 1969, 1970), then metal ion radii do not differ much from the table values. 


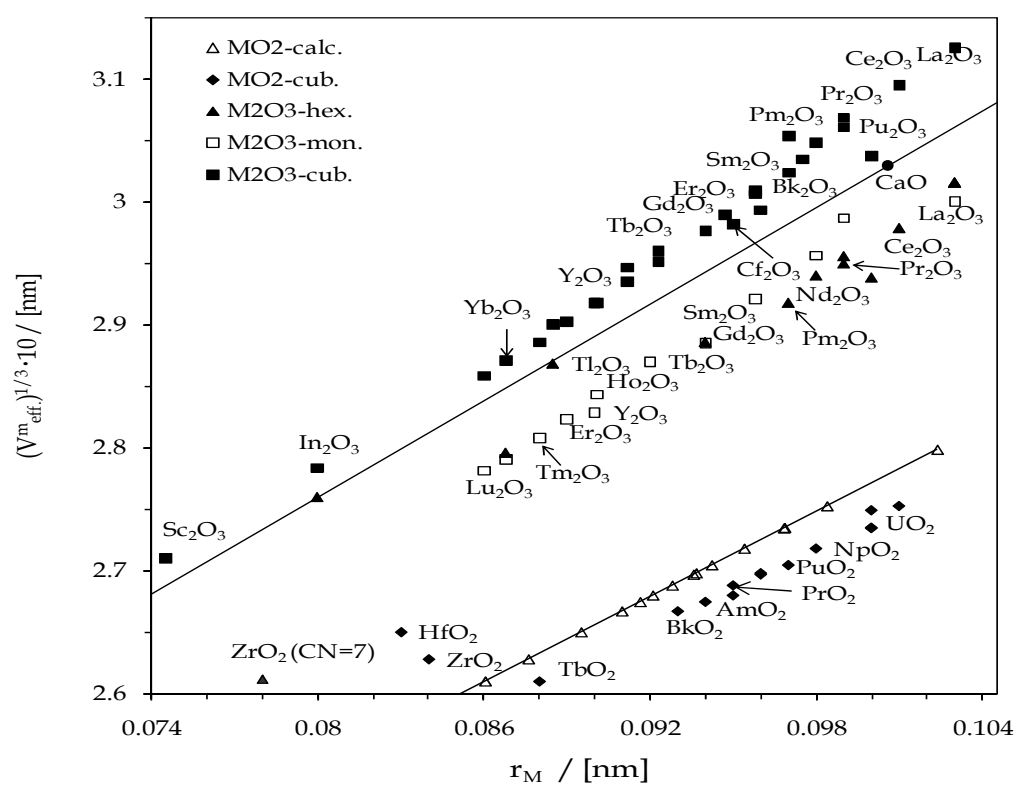

Fig. 6. The relation between the cube root of the molecular volume of $f$-electron metal oxides $\left(V_{\mathrm{eff}}^{\mathrm{m}}\right)^{1 / 3}$ and the radius of cations with coordination number 6 and 8 (the trend lines were evaluated for alkaline earth metal oxides and for $\mathrm{MO}_{2} f$-electron metal oxides ( $r_{\mathrm{M}}$ calculated for $\left.r_{\mathrm{O}}=0.140 \mathrm{~nm}\right)$ ).

\subsection{Relative ionic radii in polymorphic forms of oxides}

The introduced concept of relative radius of metal ion (relative radius of the sphere occupied by ion) in compact structures opens up the possibility for evaluation of the relative radius (sphere) of metal ions also in polymorphic forms of a given oxide. Using the experimental values of the effective molecular volume of a given polymorphic oxide form and respective equations (Eq.(4)-(6)) it is possible to calculate the effective radius of the sphere occupied by metal ion in individual polymorphic forms. The calculated values of ion radii in a series of polymorphic oxide forms are given in Table 2 of the work (Stokłosa \& Laskowska, 2008b). For illustration, the points corresponding to the $\left(V_{\text {eff }}^{\mathrm{m}}\right)^{1 / 3}$ values for polymorphic forms of many oxides and to the metal ion radii (Shannon \& Prewitt, 1969, 1970, 1976) have been plotted in Fig. 6 and Fig. 7.

As can be seen from Fig. 6, $\mathrm{M}_{2} \mathrm{O}_{3}$ oxides of $f$-electron metals with $\mathrm{La}_{2} \mathrm{O}_{3}$-type hexagonal structure and $\mathrm{Sm}_{2} \mathrm{O}_{3}$-type monoclinic structure show practically the same relationship, which indicates that in the monoclinic systems a shift of atoms occurs, but real deformation of structure is small. These oxides have smaller volumes than it would result from the relations for other oxides of this type, with ions having coordination number 6, which may be considered anomalous. They have high cohesive enthalpies and high melting temperatures, being a result of strong interactions between the $\mathrm{M}^{3+}$ ions and the oxygen. 
Therefore, as a result of interionic interactions a shortening of bond lengths and also of oxygen ion radius occurs. It is big enough that in the $\mathrm{M}_{2} \mathrm{O}_{3}$ oxides of $f$-electron metals with hexagonal and monoclinic structure the effective radii of metal ions should be smaller by about $0.040 \mathrm{~nm}$ (with $r_{\mathrm{O}}=0.14 \mathrm{~nm}$ ). Bigger molecular volumes are found for $\mathrm{M}_{2} \mathrm{O}_{3}$ oxides of f-electron metals with cubic structure being formed at higher temperatures, e.g., by the reduction of $\mathrm{MO}_{2}$ oxide.

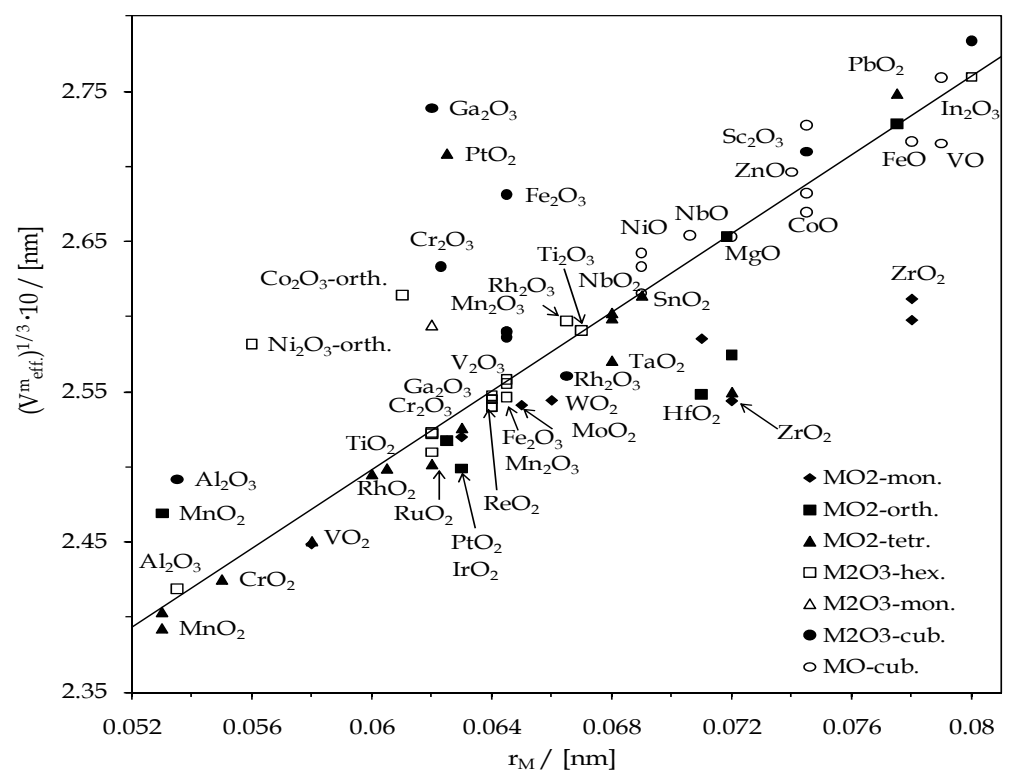

Fig. 7. The relation between the cube root of the molecular volume of oxides and their polymorphic forms $\left(V_{\text {eff }}^{\mathrm{m}}\right)^{1 / 3}$ and the radius of cations with coordination number 6 (the trend lines were evaluated for the alkaline earth metal oxides)

As can be seen from Fig. 7 the polymorphic forms of oxides: $\mathrm{MnO}_{2}$ with orthorhombic structure, $\mathrm{Al}_{2} \mathrm{O}_{3}, \mathrm{Cr}_{2} \mathrm{O}_{3}$ with cubic structure, $\mathrm{Mn}_{2} \mathrm{O}_{3}, \mathrm{Fe}_{2} \mathrm{O}_{3}$, and $\mathrm{PbO}_{2}$ with tetragonal structure, $\mathrm{Rh}_{2} \mathrm{O}_{3}$ with hexagonal structure, $\mathrm{In}_{2} \mathrm{O}_{3}$ with cubic structure have molecular volumes bigger than those resulting from their radii (tabulated values). This fact indicates that at higher temperatures, in which these forms are stable, the sphere occupied by ions in this oxide became larger and in such a structure larger radii should be attributed to metal ions (assuming constant oxygen ion radius). On the other hand, the oxides: $\mathrm{ReO}_{2}, \mathrm{PtO}_{2}$ with tetragonal structures and $\mathrm{Rh}_{2} \mathrm{O}_{3}$ with an orthorhombic structure have smaller molecular volumes than it would result from the size of their ions. The ions of these metals strongly interact with oxygen ions, which leads to the shortening of bond lengths (and also oxygen ion radius) and as a result, also the molecular volume decreases. Besides, a distortion of coordination polyhedra occurs in these oxides, which results in different $\mathrm{M}-\mathrm{O}$ bond lengths, and thus also "radii" of ions are different. Most of these forms were created under high pressure. 


\subsection{Mean relative ionic radii in non-stoichiometric oxides and mixed-valence oxides}

In the case of $d$-electron oxides the increase in oxygen pressure leads to a change in the concentration of ionic defects or at a given oxygen pressure a transformation occurs, often into a mixed-valence oxide. In this type phases metal ions are in different oxidation states and their ratio, in the case of defect concentration change, undergoes continuous changes or assumes a defined value, as in spinel structures or in ordered phases, e.g., Magnéli phases. As it was shown in the chapter 2, in spite of the fact that in the structure of the above oxide phases $\left(\mathrm{M}_{\mathrm{a}} \mathrm{O}_{\mathrm{b}}\right)$ there are cation and/or anion vacancies or cations occupy octa- or/and tetrahedral voids (as in spinel structures), their molar volumes are linear functions of the composition (in the composition range of $0.5<a / b<1$ ). These phases are thermodynamically stable, they undergo mutual transformations and they have compact structures. The above facts indicate that for this type of oxide phases a mean effective metal ion radius could be introduced. Such radius would indicate trends in the changes in the interactions of metal ions depending on their content (oxygen composition), ion charge, but also variable ratio of ions in different oxidation states. Their positions in the case of non-stoichiometric compounds are practically impossible to determine (due to electron delocalization). Thus, using Eq.(5) and the values of the effective molecular volume for oxide phases with metal ions with coordination number 6 , one can calculate the mean effective radius of metal ions in a given oxide (relative to constant oxygen radius). The mean relative ionic radii in $\mathrm{Ti}$ and $\mathrm{V}$ oxides showing deviations from stoichiometric compositions and in mixed-valence oxides is given in Table 3 of the work (Stokłosa \& Laskowska, 2008b).

\subsection{Alternative method for mean ionic radii calculation}

The linear relations between the effective molar volume of the oxides of the same metal $\left(\mathrm{M}_{a / b} \mathrm{O}\right)$ and their composition, discussed in the chapter 2 and the dependence of $\left(V_{\mathrm{eff}}^{\mathrm{m}}\right)^{1 / 3}$ on ionic radii indicate that there should be also a simple correlation between $\left(V_{\text {eff }}^{\mathrm{m}}\right)^{1 / 3}$ and the $a / b$ ratio. The relation between $\left(V_{\text {eff }}^{\mathrm{m}}\right)^{1 / 3}$ and the $a / b$ ratio for the oxides of Ti and $\mathrm{V}$, and for the oxides of $\mathrm{Ce}, \mathrm{Pr}$ and $\mathrm{Tb}$ is shown in Fig. 8. As can be seen, linear relationships have been obtained, with a high correlation coefficient, $\mathrm{R}^{2}>0.98$. Table 4 in the work (Stokłosa \& Laskowska, 2008b) contains parameters of the obtained linear functions:

$$
\sqrt[3]{\mathrm{V}_{\mathrm{eff}}^{\mathrm{m}}}=\mathrm{A} \mathrm{a} / \mathrm{b}+\mathrm{B}
$$

Comparing the dependence of $\left(V_{\text {eff }}^{\mathrm{m}}\right)^{1 / 3}$ on the ion radii $\left(r_{\mathrm{M}}\right)$ and on the $a / b$ ratio (Eq.(3) and Eq.(7)) for the oxides of the same metal exhibiting compact structures, one can obtain the equation allowing the mean effective radius of ions in oxides $\left(\mathrm{M}_{a / b} \mathrm{O}\right)$ with a given composition ( $a / b$ ratio) to be predicted:

$$
\overline{r_{M}}=(A a / b+B-\beta) / a=\gamma a / b+\delta
$$

Thus, this is an alternative method for the estimation of the mean ion radius in mixedvalence oxides or in non-stoichiometric oxides, using values of metal ion radii in various oxides of the same metal. The above method allows for the prediction of a mean ionic radius in oxides having so much deformed structure that it is difficult to determine the coordination number of metal ions or this number changes with the oxidation state. 

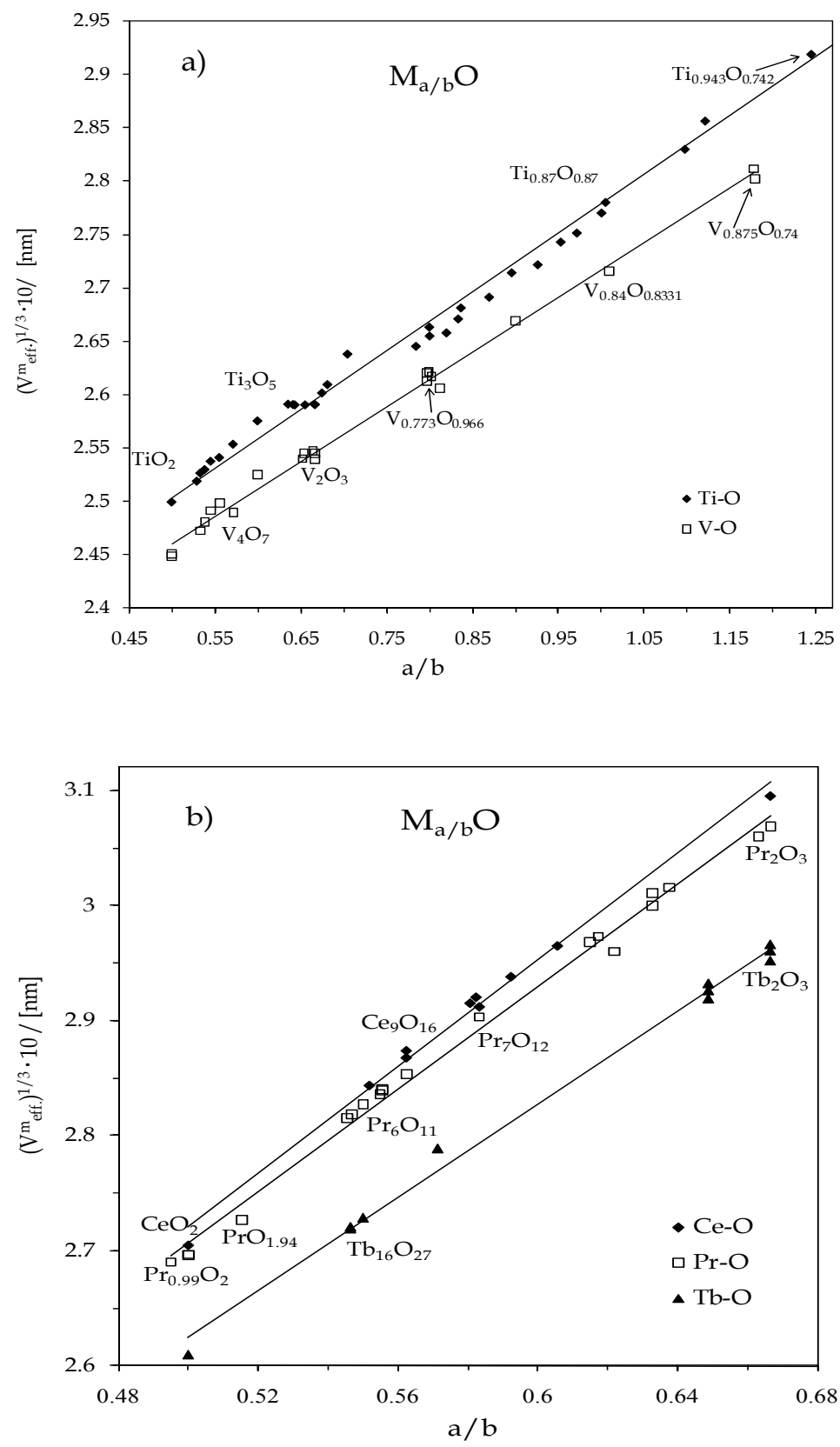

Fig. 8. The relation between the cube root of the molecular volume $\left(V_{\text {eff }}^{\mathrm{m}}\right)^{1 / 3}$ of oxide phases $\mathrm{M}_{a / b} \mathrm{O}$ and the $a / b$ ratio for the metal oxides: a) Ti and $\left.\mathrm{V}, \mathrm{b}\right) \mathrm{Ce}, \mathrm{Pr}$ and $\mathrm{Tb}$. 
Assuming the table values of the radii of $\mathrm{M}^{4+}$ and $\mathrm{M}^{3+}$ ions the values of mean radii of $\mathrm{Ti}$ and $\mathrm{V}$ ions in a series of oxide phases of these metals have been calculated. They are given in in Table 3 of the work (Stokłosa \& Laskowska, 2008b). Similarly, ion radii in the oxide phases of $\mathrm{Ce}, \mathrm{Pr}$ and $\mathrm{Tb}$ have been calculated, which was impossible with the previous method.

\subsection{Distances between oxygen ions in oxides}

In most metal oxides the compact structure the oxygen anions sublattice has the symmetry of a close-packed structure with cations in its voids. Due to the size of cation radii and repulsive interactions, mainly between oxygen ions, distances between oxygen nodes are normally higher than the sum of their radii. The parameter indicating the difference in space-filling by ions and the change of bond character in oxide (M-O) is the distance between oxygen atoms.

The interionic distances can be easily calculated for non-deformed structures (ideal geometric structures), thus in the oxides with $\mathrm{NaCl}$ - or $\mathrm{CaF}_{2}$-type cubic structures. In oxides with $\mathrm{Al}_{2} \mathrm{O}_{3}$-type hexagonal structure or $\mathrm{TiO}_{2}$-type tetragonal structure there are different bond lengths and different distances between oxygen atoms. For example, in $\mathrm{TiO}_{2}$ (rutile) the shortest distance between oxygen atoms is $d=0.252 \mathrm{~nm}$ (Vos, 1977; Meogher \& Lager, 1979), whereas in $\mathrm{SiO}_{2}$ (quartz) $d=0.260 \mathrm{~nm}$, and in its high-pressure form $d=0.216 \mathrm{~nm}$ ( Shannon \& Prewitt, 1969, 1976). Furthermore, in $\mathrm{Ti}_{2} \mathrm{O}_{3} d=0.279 \mathrm{~nm}$ (Rice \& Robinson, 1977), $\mathrm{V}_{2} \mathrm{O}_{3} d=0.279 \mathrm{~nm}$ (Robinson, 1975), $\mathrm{Fe}_{2} \mathrm{O}_{3} d=0.262 \mathrm{~nm}$ (Newnham \&Haan, 1962), and in $\alpha-\mathrm{Al}_{2} \mathrm{O}_{3} d=0.252 \mathrm{~nm}$ (Shannon \& Prewitt, 1969). As it can be seen, in many oxides the shortest $\mathrm{O}-\mathrm{O}$ distance is smaller than $0.28 \mathrm{~nm}$ (twice the table value of oxygen ion radius, $r_{\mathrm{O}}=0.14 \mathrm{~nm}$ ). For the analysis of distances between oxygen ions in oxides with typical structures, the relation between the difference between spheres occupied by oxygen atoms $(\Delta=\mathrm{d}-0.28)$ and the effective radius of metal ion has been presented in Fig. 9 (Stokłosa \& Laskowska, 2011). The reference distance is equal to a double oxygen ion radius, $2 \mathrm{r}_{\mathrm{O}}=0.28$ $\mathrm{nm}$. The distances $d$ between oxygen atoms were calculated using lattice parameters, assuming ideal structure of an oxide of a given type. As it can be seen in Fig. 9 many linear correlations were obtained. A correlation is found for the $\mathrm{M}_{2} \mathrm{O}$ alkali metal oxides. In the $\mathrm{Li}_{2} \mathrm{O}$ oxide the distance between spheres occupied by oxygen atoms is $0.04 \mathrm{~nm}$, in the case of $\mathrm{K}_{2} \mathrm{O} 0.175 \mathrm{~nm}$, and in $\mathrm{Rb}_{2} \mathrm{O}$ as much as $0.198 \mathrm{~nm}$. Similarly good linear relation was found in the case of $\mathrm{MO}$ oxides with $\mathrm{NaCl}$-type cubic structure (the trend lines were evaluated for the alkaline earth metal oxides).

The smallest $\mathrm{M}^{2+}$ ion is $\mathrm{V}^{2+}$ and also in $\mathrm{VO}$ oxide the distance between the spheres occupied by the oxygen ion is the shortest and equals only $0.013 \mathrm{~nm}$. It should be noted that $\mathrm{VO}$ and $\mathrm{TiO}$ show significant point defects concentrations in cation sublattice and oxygen sublattice and in $\mathrm{NbO}$ oxide $25 \%$ lattice nodes is unoccupied. With the increase of metal ion radius also the distance between oxygen ions increases and in the case of $\mathrm{BaO}$ it equals $0.179 \mathrm{~nm}$.

In the case of $\mathrm{MO}_{2}$ oxides with $\mathrm{TiO}_{2}$-type tetragonal structure with deformed $\mathrm{MO}_{6}$ octahedrons, for the analysis of the changes in differences $\Delta$ the distances between oxygen atoms laying in planes (000) and (001) were compared. This distance equals $c$ parameter $(d=c$ in tetragonal lattice). As it can be seen in Fig. 9, the correlations were obtained 
separately for two oxide groups, which indicates that the structures of these oxides are deformed in different ways.

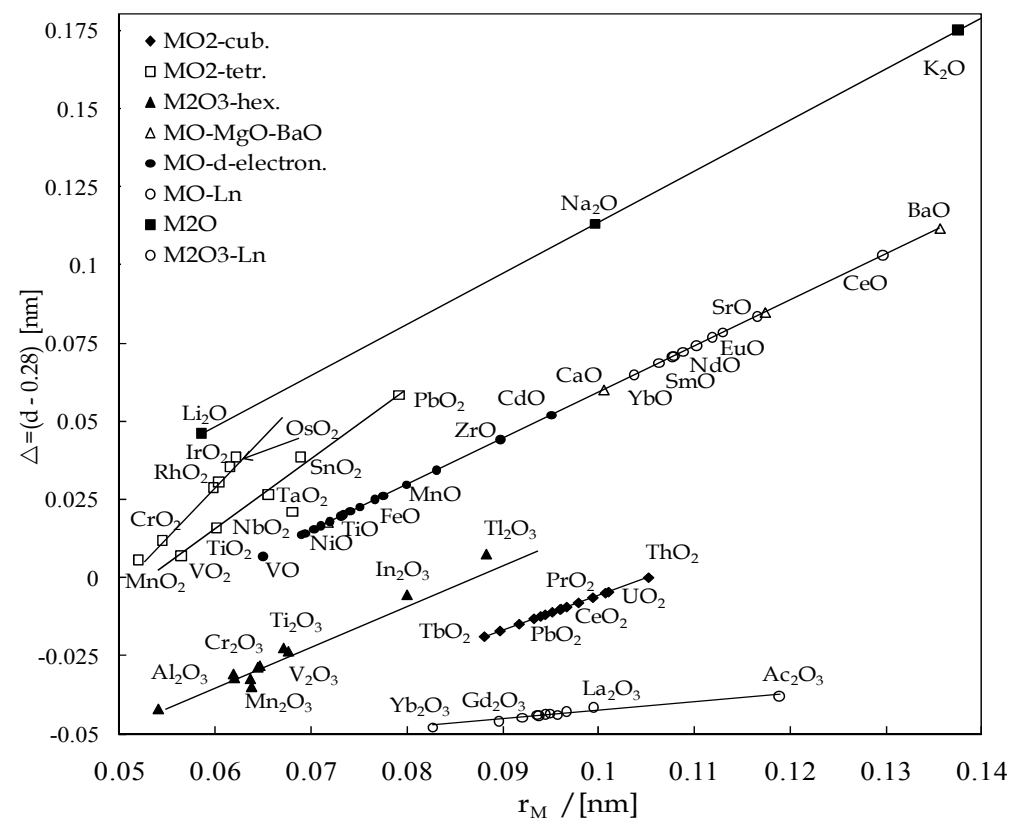

Fig. 9. The dependence of the distances between the spheres occupied by oxygen atoms $\left(\Delta=\mathrm{d}-2 \mathrm{r}_{\mathrm{O}}\right)$ where $\left.\mathrm{r}_{\mathrm{O}}=0,28 \mathrm{~nm}\right)$ and the ionic radii of metals in $\mathrm{M}_{2} \mathrm{O}$ oxides with anti-CaF structure, $\mathrm{M}_{2} \mathrm{O}_{3}$ oxides with a- $\mathrm{Al}_{2} \mathrm{O}_{3}$ structure, and $\mathrm{MO}_{2}$ oxides with $\mathrm{CaF}_{2}$ and $\mathrm{TiO}_{2}$ structure.

In the case of $\mathrm{M}_{2} \mathrm{O}_{3}$ oxides of $\mathrm{a}-\mathrm{Al}_{2} \mathrm{O}_{3}$-type, having similarly deformed oxygen octahedrons, the $\mathrm{O}-\mathrm{O}$ distance equal a half of the lattice parameter was assumed in calculations. As it can be seen in Fig. 9, for $\mathrm{M}_{2} \mathrm{O}_{3}$, with the exception of $\mathrm{Tl}_{2} \mathrm{O}_{3}$, negative values of $\Delta$ have been obtained, and this function has linear character similarly as functions for other oxides. The smallest radius is found for the aluminium ion, $0.054 \mathrm{~nm}$. It is comparable to the void size in an ideal close-packed structure of oxygen ions, the void radius being $0.058 \mathrm{~nm}$ (assuming the oxygen radius equals $0.14 \mathrm{~nm}$ ). Negative values of distances between the spheres occupied by oxygen ions $(\Delta)$ indicate that these spheres in the $\mathrm{M}_{2} \mathrm{O}_{3}$ with a- $\mathrm{Al}_{2} \mathrm{O}_{3}$ structure undergo deformations. This is related to the fact that only $2 / 3$ of octahedral voids in hexagonal close-packing structure of oxygen ions is occupied by metal atoms, whereas optimal interactions span through the entire volume of the crystal. This leads to shifts of metal ions and also of oxygen ions comparing to the ideal close-packed structure. As a result, most $d$ distances between oxygen atoms are bigger than $0.28 \mathrm{~nm}$. Small distances between spheres occupied by oxygen atoms in these oxides indicate that in these oxides strongly polarized $\mathrm{M}-\mathrm{O}$ bond must be present. A confirmation of this fact is the highest cohesive enthalpy of $\mathrm{a}-\mathrm{Al}_{2} \mathrm{O}_{3}$ and also its melting temperature; similarly high melting temperatures are observed for remaining $\mathrm{M}_{2} \mathrm{O}_{3}$ oxides with hexagonal structures. If the 
deformation of oxygen atoms arrangement had not occurred, and if the spheres occupied by oxygen ions had been in contact, then, as it can be seen from Fig. 9, the oxygen ion radius would have been smaller by $0.021 \mathrm{~nm}$. In this case the radius of octahedral void (inter) is $0.049 \mathrm{~nm}$ and the radius of the sphere occupied by the aluminium ion could not be bigger than this value.

As it can be seen in Fig. 9, the $\mathrm{MO}_{2}$ oxides of $f$-electron metals similarly have negative values of parameter $\Delta$ (the distance between the spheres occupied by oxygen ions). In the structure of these oxides, contrasting with the previous ones, metal ions have an arrangement typical for close-packing lattices. If we assume, that in $\mathrm{TbO}_{2}$ oxide the oxygen ion spheres come in touch, then the oxygen ion radius should be $r_{O}=0.131 \mathrm{~nm}$. It is therefore smaller than that proposed by Shannon and Prewitt $\left(r_{O}=0.138 \mathrm{~nm}\right.$ for $\mathrm{CN}=4$ (Shannon \& Prewitt 1969)). If we assume that this value of oxygen ion radius in other oxides remains constant, then, as it can be seen in Fig. 9, the distances between the spheres occupied by oxygen ions increase with the increase of metal ion radius in the next $\mathrm{MO}_{2}$ oxides and for the $\mathrm{ThO}_{2}$ oxide this distance will equal $0.019 \mathrm{~nm}$. In the case of $\mathrm{MO}_{2}$ lanthanide and actinide oxides, their bond energies and melting temperatures increase with the increase of the distances between oxygen ions (highest melting temperature is observed for $\mathrm{ThO}_{2}$ ) (Lide, 2004; Stokłosa \& Laskowska, 2007a). The increase of the bond energies can be an effect of the increase in the $\mathrm{M}-\mathrm{O}$ interaction related to the electronic configuration of $\mathrm{M}^{4+}$ ions and their polarizing interaction ability. Considering the properties of a $\mathrm{M}^{4+}$ ion, the increase of bond energy can be a result of the repulsive contribution to the interaction following the increase of the distances between oxygen ions when the metal ion radius increases. Therefore, in the case of $\mathrm{MO}_{2}$ oxides of $f$-electron metals, small distances between the spheres occupied by oxygen ions can lead to the increase of the repulsive interactions, which will imply the weakening of bond energies in these oxides, on the contrary to the situation for the $d$-electron oxides.

The present analysis of the distances between the spheres occupied by the oxygen ion indicates that its radius in many oxides must change, especially in the case of small $\mathrm{M}^{3+}$ and $\mathrm{M}^{4+}$ ions and strong polarizing interaction. Shannon and Prewitt (Shannon \& Prewitt, 1969, 1976) have widely discussed the change of metal ion radius depending on the coordination number. Ziółkowski and Dziembaj (Ziółkowski \& Dziembaj, 1985a, 1985b), developing this problem, has proposed a method for the evaluation of the ion radius for coordination number 0 (radius of free ion, $r_{0}$ ), regardless of the environment. He also proposed an electrostatic hover model of crystal structure, permitting the change of both the size and form of the sphere occupied by the metal ion with a minimal radius $r_{0}$.

\subsection{Packing density}

The size of the ionic radii and the character of their interactions, dependent on the metal type, is reflected in the space packing density. Knowing the values of ionic radii one can calculate the packing density of ions in individual oxides. The relation between the packing fraction of ions and the metal ion radius is presented in Fig.10. The relative metal ion radii were used and the oxygen ion radius was assumed to be $0.14 \mathrm{~nm}$. The packing fraction was calculated as the ratio of the volume occupied by ions $\left(\mathrm{V}_{\mathrm{at}}\right)$ to the volume of the unit cell calculated from lattice parameters $\left(\mathrm{V}_{\mathrm{x}}\right)$. 


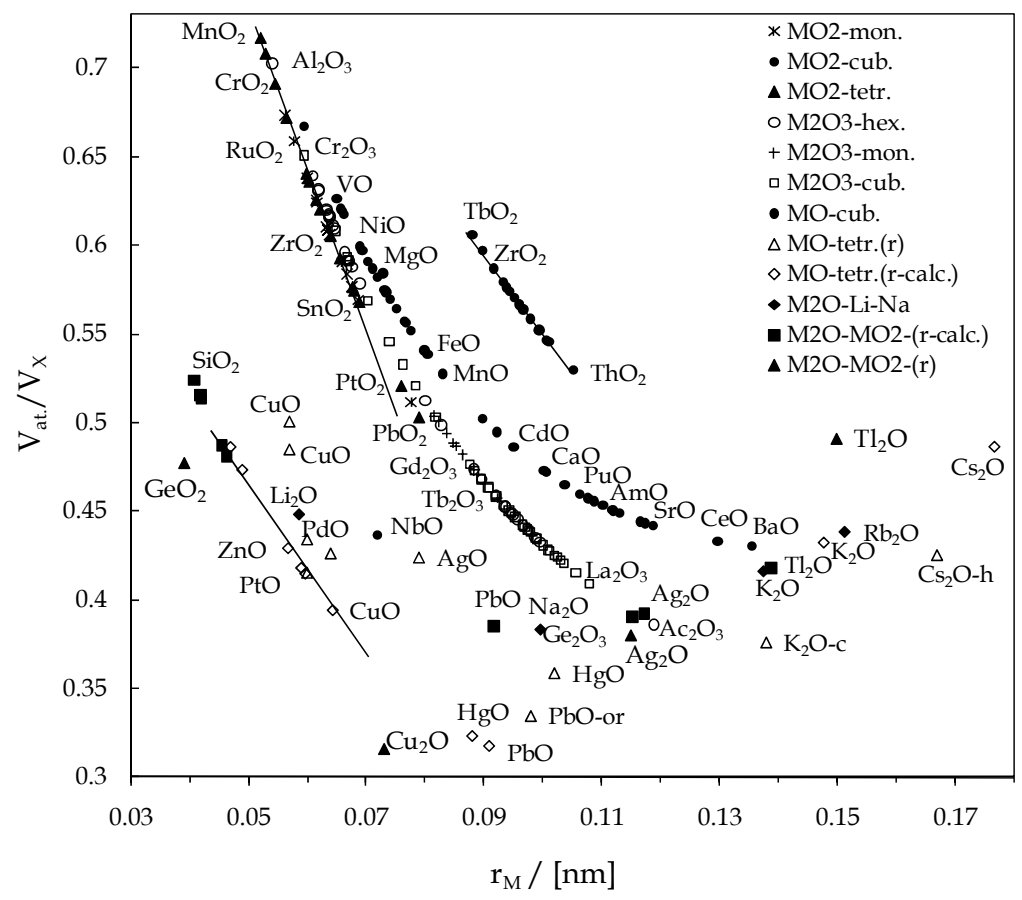

Fig. 10. The dependence of the packing density of a series of metal oxides with compact structures on the ionic radii calculated using relative ionic radii.

As it can be seen in Fig. 10, a monotonic relationship between the packing fraction and metal ion radii was obtained for the oxides of the same type forming compact structures. It is worth noticing that the packing fractions of oxides of the same type, of different metal differ rather significantly. The $\mathrm{MO}_{2}$ oxides, except for $\mathrm{PtO}_{2}$ and $\mathrm{PbO}_{2}$, lay on a straight line, whereas the curve determined by $\mathrm{M}_{2} \mathrm{O}_{3}$ and $\mathrm{MO}_{2}$ oxides deviates with the increase of the ionic radius. On the other hand, the $\mathrm{MO}_{2}$ f-electron metal oxides, with relatively big radii, have a significant packing fraction, close to the MO $d$-electron metal oxides, having metal ions of about $30 \%$ smaller. A different relationship character is observed for alkali metal oxides that, as it was mentioned, have an anti- $\mathrm{CaF}_{2}$ structure, and one should expect the relationship character similar to this for oxides with a $\mathrm{CaF}_{2}$ structure. (In the structure of these oxides metal ions have an arrangement typical for close-packing lattice with oxygen ions occupying its voids). The points for $\mathrm{Cu}_{2} \mathrm{O}, \mathrm{Ag}_{2} \mathrm{O}$ and $\mathrm{Tl}_{2} \mathrm{O}$ lay close to the curve for the alkali metal oxides. That indicates that the composition of these oxides $\left(\mathrm{M}_{2} \mathrm{O}\right)$ approaches them considering packing to the alkali metal oxides. On the other hand, $\mathrm{SiO}_{2}$ and $\mathrm{GeO}_{2}$ oxides and $\mathrm{MO}$ oxides with hexagonal structure form a separate straight line. Close to it is the point for $\mathrm{Li}_{2} \mathrm{O}$. Despite the small ionic radii of these metals, these oxides have a small packing fraction, related to a characteristic structure of framework bonds typical for covalently bonded compounds (diamond-type). For comparison, the points calculated for ions with $\mathrm{CN}=4$ (Eq.(4)) were plotted for the oxides of this group. The calculated packing fraction does not change much. 
An important issue is a change in packing density in oxides of the same metal, thus in oxides with ordered structures and showing significant deviation from the stoichiometry. The relations between the packing fraction and the $a / b$ ratio for the oxides of $\mathrm{Ti}, \mathrm{V}$ and $\mathrm{Ce}$, $\mathrm{Pr}, \mathrm{Tb}$ are shown in Fig. 11.
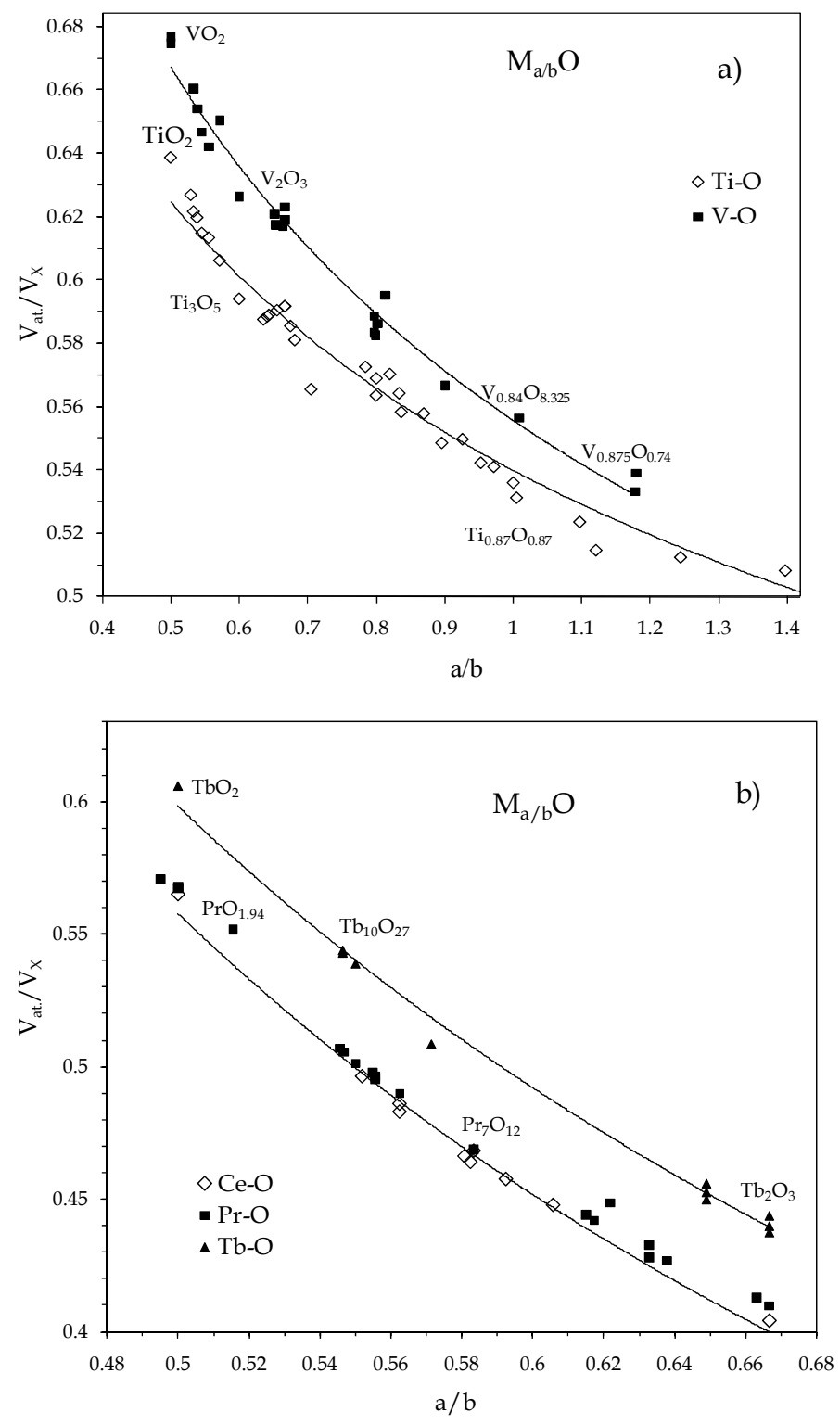

Fig. 11. The dependence of the packing density in the oxide phases $\left(\mathrm{M}_{\mathrm{a}} \mathrm{O}_{\mathrm{b}}\right)$ of metals: a) Ti and $\mathrm{V}, \mathrm{b}) \mathrm{Ce}, \mathrm{Pr}$ and $\mathrm{Tb}$ on the $a / b$ ratio, calculated using mean ionic radii. 
Average ionic radii were used in the calculations. This fraction, as it can be seen, decreases monotonically with the increase of metal content in the oxide (increase of $a / b$ ratio). It should be noted that the determined ionic radii or interionic distances reflect only ion positions in a frozen structure (in which the lattice parameters are determined). At high temperatures and in the equilibrium state the displacements of ions/atoms occur, so their positions can differ from those in frozen structures. Before all, the optimization of interactions and also of interatomic distances occur. Nevertheless information about the possibilities for modification of the sphere occupied by ions, and of packing fraction, is important for many crystal properties at high temperatures, e.g. diffusion of ions. This results from the fact that moving ions cause local deformation in their close environment.

\section{Conclusions}

Basing on the presented analysis of the molar volume of oxides the following conclusions can be formulated:

- The effective molar volume of the oxide $V_{\text {eff }}=V_{\mathrm{M}_{\mathrm{a} / \mathrm{b}} \mathrm{O}}$ (per one mole of oxygen atoms) is a parameter allowing to compare oxides with different compositions, structures and with ions in different oxidation states.

- In the composition range $1>a / b>0.5$ (and in the case of actinide oxides up to $a / b<0.35$ ) the oxides undergoing mutual transformations have compact structures, and the effective molar volumes of the oxides of the same metal decrease with the decrease of its content (with decreasing $M / O$ ratio). This type of relationship can be an additional criterion to classify an oxide of a given structure as a compact structure. The polymorphic variations of these oxides will have compact structures, because slight changes of their molar volumes, caused by changes of ion positions are the result of the changes of temperature or pressure.

- In the composition range $0.25<a / b<0.5$ the oxides form usually structures with bigger volume than the $\mathrm{MO}_{2}$ oxides. The observed increase of the effective volume with the decrease of the metal content is the result of the increase of the effective repulsive forces contribution caused by the increase of the amount of oxygen atoms relatively to metal and the strong repulsive interaction of ions with high charges, $\mathrm{M}^{5+}$ and/or $\mathrm{M}^{6+}$. This leads to the formation of structures with loose space packaging (comparing to the $\mathrm{MO}_{2}$ oxides). The presence of ions in high oxidation states, as well as a significant contribution of the covalent bond (the formation of hybrid spd orbital) results in quite high cohesive enthalpies of these oxides. As a result, the formed framework structures are stable.

- The $\sqrt[3]{V_{\text {eff }}^{\mathrm{m}}}$ parameter (cube root from the molecular volume - the volume of an oxide containing one $\mathrm{M}_{a / b} \mathrm{O}$ molecule) for the oxides with composition $0.5<a / b<2$ (from $\mathrm{M}_{2} \mathrm{O}$ to $\mathrm{MO}_{2}$ ) forming compact structures for individual groups of oxides with coordination numbers 4,6 or 8 shows linear dependence on the ion radius.

- Using experimental relations for alkali metal oxides, alkaline earth metal oxides and $\mathrm{MO}_{2}$ f-electron metal oxides with $\mathrm{CaF}_{2}$ structure, the effective metal ion radii relative to constant oxygen ion radius equal $0.140 \mathrm{~nm}$ may be determined for oxides with compact 
structures. This method allows the relative radius (sphere radius) of metal ion in polymorphic form of oxides to be calculated.

- Using the concept of a compact structure and the above method of relative ionic radii calculation, mean ion radii in oxides showing deviations from the stoichiometric composition and in mixed-valence oxides, or generally in ordered phases may be determined. Such radius indicates trends in the changes in interactions of metal ions depending on ion charge, their number (oxide composition), but also on the variable ratio of ions in different oxidation states of the metal.

- Assuming radii values determined in relation to constant oxygen radius $\left(r_{O}=1.4 \mathrm{~nm}\right)$ a linear dependence of the difference in distances between spheres occupied by the oxygen ion $(\Delta)$ on the radius of the metal ion was obtained. For a series of $\mathrm{M}_{2} \mathrm{O}_{3}$ oxides with $\mathrm{a}-\mathrm{Al}_{2} \mathrm{O}_{3}$ structure and $\mathrm{MO}_{2}$ lanthanides and actinides negative values were obtained of the difference between the distance between oxygen atoms and their double radius; this indicates that the real sphere occupied by oxygen ions must be smaller than the assumed oxygen radius $(0.14 \mathrm{~nm})$ or/and lattice deformations occur. The oxygen radius depends on the metal type and on its polarizing abilities (strength of polarized $\mathrm{M}-\mathrm{O}$ bond).

- The packing density depends on the ion radius and on the character of interatomic interaction (with ionic-covalent character) which is reflected in the different character of the relation between the packing density and cation radius. These relations are obviously different in the case of $\mathrm{MO}$ and $\mathrm{M}_{2} \mathrm{O}_{3}$ oxides of $d$ - and $f$-electron metals and $\mathrm{MO}_{2}$ oxides of $f$-electron metals compared to alkali metal oxides and metal oxides with framework structure with dominating covalent interaction.

- $\quad$ The work (Stokłosa \& Laskowska, 2007a, 2007b) presented the study on the properties of oxides of main group metals and $d$ - and $f$-electron metals in relation to the bond energy and the cube root of molecular volume. The cohesive enthalpy per one mole of oxygen atoms was used to compare the bond energy of oxides of various composition. The value of this enthalpy was calculated from thermochemical data. A linear relation between the cohesive enthalpy and the composition was found for oxide phases of the same metal. The changes in electrical properties of the oxides and the concentration of electronic and ionic defects in relation to the above parameters have been discussed. The reasons for the formation of many oxide phases of the same metal, the formation of ordered phases and the formation of phases having significant deviation from the stoichiometric composition were investigated.

\section{Acknowledgments}

The author are very grateful to Drs S.S. Kurek and B. Laskowska for valuable help and discussion.

\section{References}

Adams, D.M. (1974). Inorganic Solids, An Introduction to Concepts in Solid State Structural Chemistry, Wiley, London, ISBN 0471004707 
Ahrens, L.H. (1952). The use of Ionization Potentials. Part 1. Ionic Radii of the Elements Geochim. et Cosmochim. Acta, Vol.2, No. 3, pp. 155-169

Ahrens, L.H. (1953). The use of Ionization Potentials. Part 2. Anion Affinity and Geochemistry, Geochimica Cosmochimca Acta, Vol.3, No.1, pp 1-29

Allen, L.C. (1998). Electronegativity and the Periodic Table, in: Encyclopedia of Computational Chemistry, P. Schleyer, (Ed.), J. Wiley, New York

Allred, A.L. \& Rochow, E.G. (1958). A Scale of Electronegativity Based on Electrostatic Force, J. Inorg. Nucl. Chem. Vol.5, No.4, pp.264-268

Brisse, F. \& Knop, O. (1968). Pyrochlores. III. X-Ray, Neutron, Infrared, and Dielectric Studies of $\mathrm{A}_{2} \mathrm{Sn}_{2} \mathrm{O}_{7}$ Stannates, Canad. J. Chem., Vol.46, pp. 859-873

Brown, J.D. (1992). Chemical and Steric Constraints in Inorganic Solids, Acta Cryst. B, Vol.48, pp. $553-572$

Brown, J.D. (2002). The Chemical Bond in Inorganic Chemistry. The Bond Valence Model, Oxford Univ. Press, New York, ISBN 0198508700

Cartledge, G.H. (1928). Studies on the Periodic System. I. The Ionic Potential as a Periodic Function, II. The Ionic Potential and Related Properties, J. Am. Chem. Soc., Vol.50, No.11, pp.2855-2872

Cartledge, G.H. (1930). Studies on the Periodic System. III. The Relation between Ionizing Potentials and Ionic Potentials, J. Am. Chem. Soc., Vol.52, No.8, pp.30763083

Donnelly, R.A. \& Parr, R.G. (1978). Elementary properties of an energy functional of the first-order reduced density matrix J. Chem. Phys. 69, No.10, 4431-4440

Fumi, F.G. \& Tosi, M.P. (1964). Ionic Sizes and Born Repulsive Parameters in the NaCl-type Alkali Halides-I: The Huggins-Mayer and Pauling Forms, II. The generalized Huggins-Mayer Form, J. Phys. Chem. Solids, Vol.25, No.1, pp. 31-52

Gazquez, J.L. \& Ortiz, E. J. (1984). Electronegativities and Hardnesses of Open Shell Atoms, J. Chem. Phys. Vol.81, No.6, pp.2741-2749

Goldschmidt, V.M. (1926). Geochemische Verteilungsgesetze der Elemente, VII, Die Gesetze der Kristallchemie, Skrifter, Norsk Videnkaps Akad. Oslo, I. Math. Naturwid. $\mathrm{KI}, \mathrm{Ig}$..

Goldschmidt, V.M. (1931). Fortschr. Mineral., Vol.15, pp. 73

Görlich, E. (1989a). The Effective Nuclear Charges and their Ralelation to the Paulin's Electronegativity Scale, Z. Phys. Chem. Leipzig, Vol.270, No.2, pp.384-388

Görlich, E. (1989b). The Effective Nuclear Charges and a Standardized Ionicity Scale, Z. Phys. Chemie Leipzig, Vol.270, No.1, pp.961-967

Görlich, E. (1990). The Effective Nuclear Charges and the Softness of the Atomic Cores, Ralelation to the Paulin's Electronegativity Scale, Z. Phys. Chem. Leipzig, Vol.271, pp 169-174

Hohenberg, P. \& Kohn, W. (1964). Inhomogeneous Electron Gas, Phys. Rev. B: Solid State, Vol.136, No.3B, pp. B864-B871

Jia, Y.Q. (1991). Crystal Radii and Effective Ionic Radii of the Rare Earth Ions, J. Solid State Chem. Vol.95, No.1, pp.184-185

Kohn, W.;. Becke, A.D., \&. Parr R.G. (1996). Density Functional Theory of Electronic Structure, J. Phys. Chem., Vol.100, No.31, pp.12974-12980 
Komorowski, L. (1993) Hardness Indices for Free and Bonded Atoms, In: Structure and Bondind., Vol.80. pp. 45-70

Kunz, M. \& Brown, I.D. (1995). Out-of-Center Distortions around Octahedrally Coordinated $d^{0}$ Transition Metals, Journal of Solid State Chemistry, Vol.115, pp.395406

Lalik, E. (2005). Shannon Information as a Measure of Distortion in Coordination Polyhedral, J. Appl. Cryst., Vol.38, 152-157

Lide D.R. (ed) (2004). CRC Handbook of Chemistry and Physics, CRC Press, Boca Raton, 084930485-7

Luehen, H.; Elsenhans, U. \& Stamm, U. (1987). Low-Symmetric Coordination Polyhedra Pseudosymmetry and Idealization, Acta Cryst. A, Vol.43, pp. 187-194

Meogher, E.P. \& Lager, G.A. (1979). Polyhedral Hermale Xpansion in that Ion, Polymorphs: Refinement of the Crystal Structures Rutile and Brookite at High Temperature, Canadian Mineralogist, Vol.17, pp. 77-85

Mulliken, R.S. (1934). A New Electroaffinity Scale; Together with Data on Valence States and on Valence Ionization Potentials and Electron Affinities, J. Chem. Phys. Vol.2, pp.782-794

Mulliken, R.S. (1935). Electronic Structures of Molecules XI. Electroaffinity, Molecular Orbitals and Dipole Moments, J. Chem. Phys. Vol.3, pp. 573-586

Nespolo, M.; Ferraris, G.; Ivaldi, G. \& Hoppe, R. (2001). Charge distribution as a tool to investigate structural details. II. Extension to hydrogen bonds, distorted and hetero-ligand polyhedral, Acta Cryst. B, Vol.57, pp.652-664,

Newnham, R.E. \& de Haan Y.M. (1962). Refinement of the $a \mathrm{Al}_{2} \mathrm{O}_{3}, \mathrm{Ti}_{2} \mathrm{O}_{3}, \mathrm{~V}_{2} \mathrm{O}_{3}$ and $\mathrm{Cr}_{2} \mathrm{O}_{3}$ Structures, Zeitschrift für Kristallographie: Vol. 117, No. 2-3, pp. 235-237

O'Keeffe, M.; Navrotsky, A. (1981) (Eds.), Structure and Bonding in Crystals, Academic Press. New York, QD911:O4

Parr, R.G., \&. Pearson, R.G, (1983). Absolute Hardness: Companion Parameter to Absolute Electronegativity, J. Am. Chem. Soc., Vol.105, No.26, pp. 7512-7516,

Pauling, L. (1927). The sizes of ions and the structure of ionic crystals, J. Am. Chem. Soc., Vol.49, No.3, pp. 765-790

Pauling, L. (1929). The Principles Determining the Structure of Complex Ionic Crystals, J. Am. Chem. Soc. Vol.51, No.4, pp. 1010-1026

Pauling, L. (1932). The nature of the Chemical Bond. iv. the Energy of Single Bonds and the Relative Electronegativity of Atoms, J. Am. Chem. Soc.,, 54 No.9, pp. 35703582

Pauling, L. (1960). The Nature of the Chemical Bond, Cornell Univ. Press, Ithaca, New York,.

Pearson, R.G. (1988). Absolute Electronegativity and Hardness, Application to Inorganic Chemistry, Inorg.Chem. Vol.27, pp. 734-740,

Pearson, R.G. (1997). Chemical Hardness, J. Wiley-VCH, New York, ISBN 3-427-29482-1

Phillips, C.S.G. \& Williams, R.J.P. (1965). Inorganic Chemistry, Oxford Univ. Press, New York

Rao, C.N.R. (Ed) (1993). Chemistry of Advanced Materials, Blackwell, Oxford, ISBN 0-63203385-1 
Rao, C.N.R. \& Raveau, B. (1995). Transition Metal Oxides, VCH Publ. New York, ISBN 156081-647-3

Rice, C.E. \& Robinson WR (1977). High-Temperature Crystal Chemistry of $\mathrm{Ti}_{2} \mathrm{O}_{3}$ : Structural Changes Accompanying the Semiconductor-Metal Transition, Acta Crystall. B Vol.33, pp.1342-1348

Robinson, W.R. (1975). High-temperature Crystal Chemistry of $\mathrm{V}_{2} \mathrm{O}_{3}$ and $1 \%$ ChromiumDoped $\mathrm{V}_{2} \mathrm{O}_{3}$, Acta Crystall B Vol.31. pp.1153-116

Sanderson, R.T. (1976). Chemical Bonds and Bond Energy, Academic Press. New York

Shannon, R.D \& Prewitt, C.T. (1969). Effective Ionic Radii in Oxides and Fluorides, Acta Cryst. B, Vol.25, pp.925-946

Shannon, R.D. \& Prewitt, C.T. (1970). Revised Values of Effective Ionic Radii, Acta Cryst. B, Vol.26, pp.1046-1048

Shannon, R.D. (1976). Revised Effective Ionic Radii and Systematic Studies of Interatomic Distances in Halides and Chalcogenides, Acta Cryst. A, Vol.32, pp.751-767

Slater, J.C. (1930). Atomic Shielding Constants, Phys. Rev. Vol.36, pp.57-64

Stokłosa, A; Zajęcki, J. \& Kurek, S.S. (2004). Effective Nuclear Charge of the Ion, Materials Science-Poland, Vol. 22. No.1, 35-45

Stokłosa, A. \& Laskowska, B. (2007a). The Bond Energy and the Composition of Metal Oxides, High Temperature Materials and Processes, Vol.26, No.2, pp. 93102

Stokłosa, A. \& Laskowska, B. (2007b). Trends in the Changes of Properties of Oxides in Relation to Band Energies and Interatomic Distances. High Temperature Materials and Processes, Vol.26, No.5-6, pp. 317-339

Stokłosa A. \& Laskowska, B. (2008a) Molar Volume and Composition of Oxides of the Same Metal, J. Chem. Crystallogr, Vol.38, pp. 279-284

Stokłosa, A. \& Laskowska, B. (2008b). Ionic Radii in Mixed-Valance and Nonstoichiometric Metal Oxides and Their Polymorphic Forms, J. Chem. Crystallogr, Vol.38, pp. 913925

Stokłosa, A. \& Laskowska, B. (2011). Influence of Ionic Interactions and Ion Sizes on Their Packing Density in Metal Oxides, J. Chem. Crystallogr, Vol.41, pp. (on line)

Von Meerssche, M. \& Dupont, J.F. (1976). Introduction à la cristallographie et à la Chimie structurale, OYEZ, Luven

Vos, K (1977). Reflectance and Electroreflectance of $\mathrm{TiO}_{2}$ Single Crystals. II. Assignment to Electronic Energy Levels, J. Phys. C, Vol.10, No.19, pp. 3893- 3917

Wasastjerna, J.A. (1923). Soc. Sci. Fennica, Commentationes Phys. Math.I, Vol.38, pp.12

Wells, A.K. (1990). Structural Inorganic Chemistry, Clarendon Press, Oxford

West, A.R. (1996). Basis Solid State Chemistry, J. Wiley, Chichester, New York, ISBN 0-47198755-7 (hbk.)

Zachariansen, W.H. (1931). Z. Kristallogr., Vol.80, pp.137

Ziółkowski, J. \& Dziembaj L. (1985a). Empirical Relationship beteen Individual Cation-Oxygen Bond, Journal of Solid State Chemistry, Vol.57, No.3., pp. 291299 
Ziółkowski, J. (1985b). New Ralation between Ionic Radii, Bond Length, and Bond Strength, Journal of Solid State Chemistry, Vol.57, No.3. pp. 269-290 


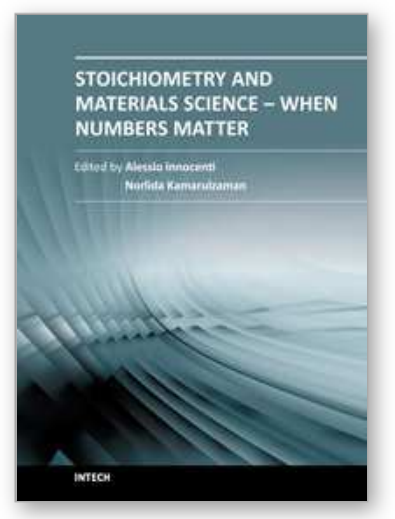

\author{
Stoichiometry and Materials Science - When Numbers Matter \\ Edited by Dr. Alessio Innocenti
}

ISBN 978-953-51-0512-1

Hard cover, 436 pages

Publisher InTech

Published online 11, April, 2012

Published in print edition April, 2012

The aim of this book is to provide an overview on the importance of stoichiometry in the materials science field. It presents a collection of selected research articles and reviews providing up-to-date information related to stoichiometry at various levels. Being materials science an interdisciplinary area, the book has been divided in multiple sections, each for a specific field of applications. The first two sections introduce the role of stoichiometry in nanotechnology and defect chemistry, providing examples of state-of-the-art technologies. Section three and four are focused on intermetallic compounds and metal oxides. Section five describes the importance of stoichiometry in electrochemical applications. In section six new strategies for solid phase synthesis are reported, while a cross sectional approach to the influence of stoichiometry in energy production is the topic of the last section. Though specifically addressed to readers with a background in physical science, I believe this book will be of interest to researchers working in materials science, engineering and technology.

\title{
How to reference
}

In order to correctly reference this scholarly work, feel free to copy and paste the following:

Andrzej Stoklosa (2012). Molar Volume, Ionic Radii in Stoichiometric and Nonstoichiometric Metal Oxides, Stoichiometry and Materials Science - When Numbers Matter, Dr. Alessio Innocenti (Ed.), ISBN: 978-953-510512-1, InTech, Available from: http://www.intechopen.com/books/stoichiometry-and-materials-science-whennumbers-matter/molar-volume-ionic-radii-bond-energies-in-stoichiometric-and-nonstoichiometric-metal-oxides-

\section{INTECH}

open science | open minds

\author{
InTech Europe \\ University Campus STeP Ri \\ Slavka Krautzeka 83/A \\ 51000 Rijeka, Croatia \\ Phone: +385 (51) 770447 \\ Fax: +385 (51) 686166 \\ www.intechopen.com
}

\author{
InTech China \\ Unit 405, Office Block, Hotel Equatorial Shanghai \\ No.65, Yan An Road (West), Shanghai, 200040, China \\ 中国上海市延安西路65号上海国际贵都大饭店办公楼 405 单元 \\ Phone: +86-21-62489820 \\ Fax: $+86-21-62489821$
}


(C) 2012 The Author(s). Licensee IntechOpen. This is an open access article distributed under the terms of the Creative Commons Attribution 3.0 License, which permits unrestricted use, distribution, and reproduction in any medium, provided the original work is properly cited. 